\title{
Absenteeism, Dropout, and On-Time School Completion of Vulnerable Primary School Students in Ethiopia: Exploring the Role of Adolescent Decision-Making Power in the Household, Exposure to Violence, and Paid and Unpaid Work
}

\author{
Tassew Woldehanna ${ }^{1} \cdot$ Kefyalew Endale ${ }^{2} \cdot$ Joan Hamory ${ }^{3} \cdot$ Sarah Baird $^{4} \mathbb{D}$
}

Accepted: 9 August 2021

(c) The Author(s) 2021, corrected publication 2021

\begin{abstract}
While Ethiopia has seen a rapid expansion of school enrollment over the past 25 years, especially in primary education, dropout, absenteeism, and grade repetition remain key challenges to achieving the education-related Sustainable Development Goals. This article uses the 2017/18 Gender and Adolescence: Global Evidence (GAGE) survey of 6800 Ethiopian adolescents and regression analysis to examine how exposure to and / or experience of violence (from peers and at home), adolescent decision-making power in the household, and paid and unpaid child work are related to absenteeism, dropout, and on-time completion in primary school. The findings provide empirical evidence on the positive association between adolescent decision-making power in the household and educational outcomes and the negative relationships between adolescent education and both exposure to and /or experience of violence and paid and unpaid child work. We explore variations in the magnitude and robustness of these associations across gender, age cohort, and rural/urban residential location. Our findings suggest that programs which enhance decision-making power of adolescents in the household reduce exposure to and/or experience of violence among peers and at home and reduce participation in paid and unpaid child work which can improve adolescent educational attainment.
\end{abstract}

Keywords Primary school - Exposure to violence $\cdot$ Adolescent decision-marking power $\cdot$ Paid and unpaid work $\cdot$ Absenteeism and dropout

JEL Classification I21

Sarah Baird

sbaird@gwu.edu

Extended author information available on the last page of the article 


\section{Resume}

Bien que l'Ethiopie a bénéficié d'une forte expansion des inscriptions scolaires sur les 15 dernières années, surtout aux cycle élémentaire, l'absentéisme, le décrochage scolaire, et les redoublement de classe restent des défis clés à la réalisation des objectifs de développement durables associés à l'éducation. Cet article utilise une enquête récente de 6800 adolescents Ethiopiens, et une analyse de régression, afin d'examiner comment l'exposition à la violence (par ses pairs, et à la maison), l'agence des adolescents, et le travail des mineurs sont relationnés a la rétention et a l'achèvement scolaire en primaire. Les résultats offrent évidence empirique sur la relation positive entre l'agence des adolescents et leurs résultats éducatifs, et sur la relation négative entre la violence et le travail des mineurs, et l'éducation des adolescents. On explore l'ampleur et la solidité de ces associations à travers le genre des adolescents, leur groupe d'âge, et leur résidence urbaine ou rurale. Les résultats suggèrent que les programmes qui augmentent l'agence des adolescents, qui réduisent la violence parmi pairs et à la maison, et qui réduisent le travail des mineurs, peuvent améliorer le rendement scolaire des adolescents.

\section{Introduction}

Increased human capital is an important component of economic growth, development, and poverty reduction (Aghion et al. 1999; Barro 1997). As such, low- and middle-income countries (LMICs) have prioritized a rapid expansion of access to education, particularly at the primary level, to increase the educational attainment of adolescents. Ethiopia is no exception. The country experienced rapid growth in primary schools from 1996-2020 that helped increase net primary enrollment in first cycle primary education (grades $1-4)^{1}$ from $87 \%$ ( $85 \%$ for females, $88 \%$ for males) in $2009 / 10$ to $104 \%$ (99\% for females, $109 \%$ for males) ${ }^{2}$ in $2019 / 20$. Net enrollment in second cycle primary education (grades 5-8) also increased-from $46 \%$ (47\% for females, $46 \%$ for males) in $2009 / 10$ to $66 \%$ (64\% for females, $67 \%$ for males) in 2016/17 (MOE 2015 and 2020).

Yet a wide gap in net enrollment persists between the first and second cycles of primary education: $87 \%$ vs. $46 \%$, suggesting that many 11-14-year-old adolescents are not progressing into the second cycle of primary education, due to grade repetition or dropout. As of 2019/20, repetition rates for grades 1-8 stood at 5\% (similar by gender) and dropout at $14 \%$. The highest incidence of dropout is recorded in grade 1 with $22 \%$. (21\% female, $22 \%$ male). Beyond repetition and dropout, another important issue is age-for-grade appropriateness which arises mainly due to grade repetition and/or late entry into school. It contributes to the widening gap between gross enrollment and net enrollment by decreasing completions of first cycle (grade 4) and second cycle (grade 8) at 10 and 14 years old, respectively. The high rates of

\footnotetext{
1 Primary education in Ethiopia is divided into two cycles of four years: first cycle (grades 1-4) for 7-10 year old children and second cycle (grades 5-8) for 11-14 year old children.

2 Enrollment rates over $100 \%$ highlight an outdated population sizes of regions and incorrect projections (as censuses are conducted once in a decade), incorrect records of child ages in schools, and the existence of migrant children enrolling in schools between regions (MOE 2016/17).
} 
dropout, non-completion of primary school, and large numbers of overage-for-grade children imply that many children are leaving school without acquiring the most basic skills, limiting their future opportunities and leading to inefficient utilization of the scarce resources allocated to education (Sabates et al. 2010).

Dropouts, absenteeism, overage-for-grade children, and weak progression into second cycle primary education will make it very difficult for Ethiopia to achieve the education-related Sustainable Development Goals (SDGs) by 2030-particularly target 4.1, which seeks 'By 2030, to ensure that all females and males complete free, equitable and quality primary and secondary education leading to relevant and effective learning outcomes' (United Nations 2019). This paper explores factors that contribute to school dropout, absenteeism, and on-time completion, focusing on the largely unexplored roles of adolescent decision-making power in the household, exposure to and/or experience of violence, and paid and unpaid work. An increased understanding of barriers to on-time primary school completion is essential to achieving the goal of no child left behind in education in Ethiopia by 2030.

School absenteeism is associated with a range of life-course problems in adolescence such as adolescent pregnancy, risky sexual behavior, and substance abuse (Gubbels et al. 2019). Excessive absenteeism, in turn, is a signal of ongoing school attrition which consequently leads to permanent dropout from school (Cabus and De Witte 2015; Kearney 2008). The challenges of absenteeism and dropout affect not only the individuals but also the society at large, through their effects on health, wealth, and the social fabric (Gubbels et al. 2019; Subrahmanyam 2016). Thus, investigating what drives absenteeism, dropout, and on-time grade completion is essential to improve outcomes for young people.

The majority of studies conducted on primary school absenteeism, dropout, and on-time school completion of adolescents in LMICs emphasize the effects of child marriage, age, gender, parental literacy, household size, economic shocks, accessibility of schools, regular school meals, and school fees (Ohba 2020; Taniguchi 2015; Woldehanna and Hagos 2015; Abuya et al. 2013; Lloyd and Mensch 2008; Chege and Sifuna 2006; Rose and Al-Samarrai 2001). However, less is understood, with no known previous evidence from Ethiopia to the best of our knowledge, about the links between exposure to and/or experience of violence, and adolescent decisionmaking power in the household on adolescent education outcomes.

Child labor is another barrier to achieving universal primary education in LMICs. Poor families often need their children to work to support the household and this decreases their education outcomes (Putnick and Bornstein 2015). According to Putnick and Bornstein (2015), there are three types of child labor: work outside the home (mostly paid), family work (such as farming), and domestic chores (such as child care) with the education research focusing on child work outside the home. Measuring child labor by the work outside the home understates the amount of work children are undertaking, especially for girls and younger adolescents, as it ignores the burden of care work (Gibbons et al. 2005). To address this research gap, two measures different of child labor are employed in this analysis: for older adolescents $(15+)$, child labor is measured by paid work, whereas for younger adolescents (14 and under) unpaid domestic care is used. 
Adolescent decision-making power in the household and exposure to and/or experiencing of violence could also intersect with child work to determine adolescents' educational outcomes. Addressing these issues ties into two other SDG targets, notably targets 4.A (to 'build and upgrade education facilities that are child, disability and gender sensitive and provide safe, non-violent, inclusive and effective learning environments for all') and 8.7 (to 'end child labor in all its forms') (United Nations 2019).

This study, therefore, aims to address this gap in the literature by investigating the roles of adolescent exposure to and/or experience of violence (at home and at school), adolescent decision-making power in the household, and paid and unpaid child work in driving absenteeism, dropout, and on-time completion of primary education. Using data from the Gender and Adolescence: Global Evidence (GAGE) longitudinal study of more than 6800 adolescents in Ethiopia, we aim to highlight the challenges facing vulnerable adolescents in accessing safe learning environments, highlighting barriers and possible policy solutions to achieving the goal of leaving no child left behind in education. Specifically, we believe this analysis helps unpack unexplored linkages between key dimensions of adolescent life-including adolescent decision-making power in the household, adolescent exposure to and/or experience of violence (at home and at school), and paid and unpaid work-and education outcomes, with important implications for achieving SDG targets.

\section{Review of the Literature}

There is a wealth of empirical literature on the determinants of primary education in sub-Saharan African (SSA) countries and other LMICs. The main determinants of enrollment and completion explored include: child characteristics, parental education, and other household characteristics (Taniguchi 2015; Kabubo-mariara and Mwabu 2007; Rose and Al-Samarrai 2001); health and poverty (King et al. 2015; Posso and Feeny 2016); parental support for children's education (Sabates et al. 2013); and school quality and services (Taniguchi 2015; Kabubo-mariara and Mwabu 2007; Glewwe and Ilias 1996; Ohba 2020). Yet there are many other potentially important challenges faced by youth that may impact their educational outcomes, including exposure to and/or experience of violence, adolescent decisionmaking power within the household, and paid and unpaid child work.

Many children in SSA experience violence in their homes, schools, communities, or at work (Pells and Morrow 2017). Violence is widespread, especially among adolescents (Marcus et al. 2019; Fonagy et al. 2005). Wandera et al. (2017), citing data from the Global School-Based Health Survey, report that about $63 \%$ of adolescents in Zambia experienced bullying at least one day in the month preceding survey, and in their own work in Uganda, the authors report rates of primary school student experience of physical and emotional violence of $29 \%$ and $34 \%$, respectively. Similarly, Psaki et al. (2017) report that over $50 \%$ of respondents in their study in rural Malawi had experienced both school-related gender-based violence and domestic violence. 
Ethiopia is no exception. Violence against children is widespread in rural and urban areas alike, and emotional abuse is common in home and in schools (Pankhurst et al. 2018). Violence can affect adolescents' educational outcomes in many ways. Peer violence can worsen depression and anxiety which can increase disruptive behaviors (Macmillan and Hagan 2004). Similarly, domestic/home violence can harm adolescents' educational outcomes through its physical and psychological effects (Lloyd 2018), and in particular by decreasing focus in the classroom and slowing academic progression (McGaha-Garnett 2013). In this analysis we focus on two types of violence that are pervasive for young people and measured in our data: (i) physical violence (i.e., when a person hurts or tries to hurt another by hitting, kicking or using other types of physical force) and (ii) psychological violence (i.e., coercion, defamation, verbal insult or harassment).

Adolescent decision-making power within the household is another factor that may contribute to educational outcomes, through improving concentration and task completion, as well as active participation through questions and answers in class (Wyness 1999). But to our knowledge there is no quantitative evidence on the relationship between adolescent decision-making power in the household and educational outcomes in Ethiopia.

Finally, there is a large literature documenting negative links between child work, class absenteeism, school dropout, and educational achievement (Bai and Wang 2020; Posso and Feeny 2016; Beegle et al. 2009; Assaad et al. 2007; Edmonds 2007; Ray and Lancaster 2005). But most of these studies emphasize work outside the home with limited attention to the effects on schooling of household chores. There are a few studies such as Putnick and Bornstein (2015), Gibbons et al., (2005) that investigated the effect of unpaid domestic caregiving in addition to the work outside home. This study contributes to the literature by examining how both paid and unpaid caregiving and work outside the home interconnects with adolescent decision-making power in the household and exposure to and/or experience of violence to drive adolescents' educational outcomes.

\section{Conceptual Framework}

Based on the empirical literature cited above, the Education Sector Development Programme of Ethiopia (ESDP V), ${ }^{3}$ and Hanushek's (1979) education attainment production function, we present a conceptual framework linking adolescent agency, child work, and violence to educational outcomes (Fig. 1). This framework provides an illustration that underpins the exploratory analysis undertaken in this paper investigating unexplored linkages between household decision-making power, exposure

\footnotetext{
${ }^{3}$ School Improvement Programme (SIP) is one of the 5 components of improving general education quality in Ethiopia which involves increasing community participation and creating favorable school environments with a proper code of conduct to reduce any form of violence and harassment in school (MoE 2015).
} 
to violence and paid/unpaid work and education outcomes, a framework that motivates our regression analysis.

The arrows in the flowchart show proposed directionality. For instance, the framework hypothesizes that decision-making power within the household will improve adolescents' concentration and performance, while work is likely to decrease these efforts. Similarly, exposure to and/or experience of violence impacts anxiety, fear, and disruptive behavior. Ultimately, these channels impact school attendance and dropout, which in turn affect on-time primary school completion and highest grade attended.

Alongside adolescent decision-making power within the household, exposure to and/or experience of violence, and paid and unpaid child work, other variables at the individual, household and community levels also drive educational outcomes (as described in the literature review above). These variables are not the focus of this study, but are controlled for in all analysis (they are shown under 'other factors' in the conceptual framework, and described in more detail here). While some of the above measures are easily captured in a quantitative survey, others, in particular adolescent decision-making in the household, are more complicated. Thus, our analysis will be limited by the data available to us to measure the underlying constructs.

Individual characteristics that must be considered include gender and health status. As we show above, there is some gender inequality in education enrollment and completion in LMICs, and this is at least partially driven by cultural beliefs which prioritize the education of males over females (Boualaphet and Goto 2020; Evans et al. 2019; Chege and Sifuna 2006). Health status likely matters because unhealthy children, such as those falling sick frequently, are both less likely to be enrolled and more likely to drop out of school (Rose and Al-Samarrai 2001). Mental distress is another health problem that affects the educational outcomes of adolescents (Rothon et al. 2009; Fergusson and Woodward 2002). It can affect adolescent educational outcomes in two ways: by increasing the risks of developing major depression at a

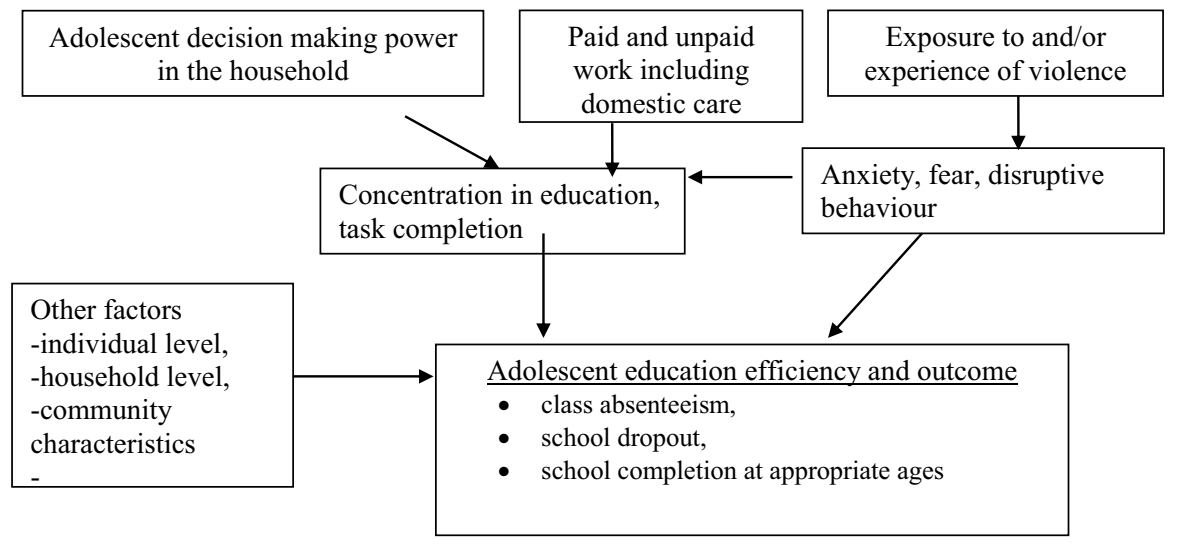

Fig. 1 Conceptual framework. This conceptual framework links child agency, child work, and experience of violence with adolescent education efficiency and outcomes. Source: Authors' construction based on Wodon et al. (2016); McGaha-Garnett (2013); Macmillan and Hagan (2004); Wyness (1999) 
later age and through its associations with individual, household, and social factors (Fergusson and Woodward 2002).

Household characteristics of importance include parental education and assets. Parental education influences children's education by improving the socioeconomic situation of the household and by enhancing parents' attitudes toward educating their children (Boualaphet and Goto 2020; Posso and Feeny 2016; Rose and Al-Samarrai 2001). Asset accumulation, is a component of household wealth which indicates ability to afford the costs of sending children to school such as school fees, uniforms, exercise books and textbooks (Basu 1999).

Finally, community characteristics such as location of residence (urban/rural), pastoralist/non-pastoralist nature of household livelihoods, and access to services are important to consider. Quality of education tends to be low in rural areas (especially remote areas) and poor educational outcomes such as dropout are higher in rural areas than urban areas (Boualaphet and Goto 2020; Posso and Feeny 2016; Bergmann 1996; Ziyn 2012).

\section{Empirical Specification}

Motivated by the conceptual framework, our empirical specification follows Hanushek's (1979) education production function $\left(A_{i}=f\left(B_{i}, P_{i}, S_{i}, I_{i}\right)\right)$, a function which is commonly employed by researchers in the analysis for school achievement of individuals. This production function notes that the education attainment for individual or student $i\left(A_{i}\right)$, is a function of $B$, a vector of family background which affects the education attainment of the individual such as literacy of the head and wealth, $P$, a vector of peers' characteristics such as peer violence; $S$, a vector of school characteristics service facility index, and $I$, a vector of individual observable characteristics such as age, gender, and unobservable characteristics such as innate abilities. Thus, we specified the following linear regression model for our estimation purposes (Eq. 1):

$$
\begin{aligned}
A_{i}= & \beta_{0}+\beta_{1} \text { Decision_Making_Power }_{i}+\beta_{2} \text { Peer_Violence }_{i}+\beta_{3} \text { Home_Violence }_{i} \\
& +\beta_{4} \text { Child_Work }_{i}+\gamma B+\delta P+\vartheta S+\mu I+u_{i}
\end{aligned}
$$

The main explanatory variables are Adolescent decision-making power within the household, measured by the extent of the adolescent have say in household decisions; Peer Violence, which is the exposure to and/or experience of the adolescent to peer violence in school, outside school, or both in and outside school; Home violence which is measured by an exposure to and/or experience of violence at home, and finally child work which can be unpaid caregiving at home or paid work outside home. Vectors B, P, S, and I are as defined above and $u_{i}$ is the error term.

Our analysis employs a linear probability model to analyze school dropouts and school completion (results are qualitatively the same using a probit model), and ordinary least square (OLS) estimation method to analyze the proportion of 
classes missed. All analyses applies sampling weights to ensure that results are representative of the study areas.

\section{Data and Methods}

The analysis presented here uses data from the GAGE Ethiopia longitudinal study. The baseline survey was conducted with 6800 adolescent females and males between late 2017 and mid-2018. We provide some detail on the sample design here, but interested readers can find a full description in Hicks et al. (2019) and refer to the methods article in this special issue.

The GAGE sample is drawn from rural, urban and pastoralist communities in the regions of Afar, Amhara and Oromia, as well as the Dire Dawa city administration. GAGE research sites were purposefully selected to represent different social, cultural and economic contexts, including differing gender norms as well as different levels of food security and vulnerability. The rural sites in Zone 5 (Afar), South Gondar (Amhara) and East Hararghe (Oromia) zones were selected on the basis of a review of existing data and evidence on adolescents and gender (such as high rates of child marriage), marginalization (in terms of access to services) and, due to a planned impact evaluation, programming capacity of implementing partners. Our midline qualitative surveys show that sites in Zone 5 (Afar) are largely dominated by people who are pastoralists where children are involved in unpaid child work such as cattle herding, while people in East Hararghe (Oromia) are heavily involved in cash crop production such as growing Khat and coffee. Children in these sites are heavily involved in paid and unpaid work. Our midline qualitative surveys also show that in South Gondar, adolescents are mainly involved in unpaid child work.

The urban sites, on the other hand, were selected to offer variation in size to contribute to ongoing debates about urbanity, as well as based on proximity to the rural sites, to better allow for urban-rural comparisons. The urban sites include Dire Dawa, Debre Tabor (South Gondar), and Batu/Ziway (Oromia). In Batu adolescents work in flower farms for pay. Hence place of residence (location) is one of the confounding factors in explaining adolescent's achievement in education. See Fig. 2 for a map of GAGE research locations in Ethiopia.

The 6800 GAGE focal adolescents were chosen through a combination of random sampling from a census style door-to-door listing and purposeful sampling to ensure that vulnerable adolescents (such as those who are out of school, married, or have disabilities) were included in the sample. ${ }^{4}$ Adolescents include individuals aged 10-19 years old. Due to GAGE's interest in understanding how challenges of adolescents change over time, but with budget constraints that would make a large sample of adolescents of all ages in this range difficult to obtain, the research team opted to collect data on a sample of very young adolescents (aged 10-12 at baseline) and a sample of older adolescents (aged 15-17 at baseline). These two groups are

\footnotetext{
${ }^{4}$ Due to the dual random and purposeful sampling strategy described above, all regression analysis presented below includes an indicator for whether a given adolescent was part of the random sample.
} 


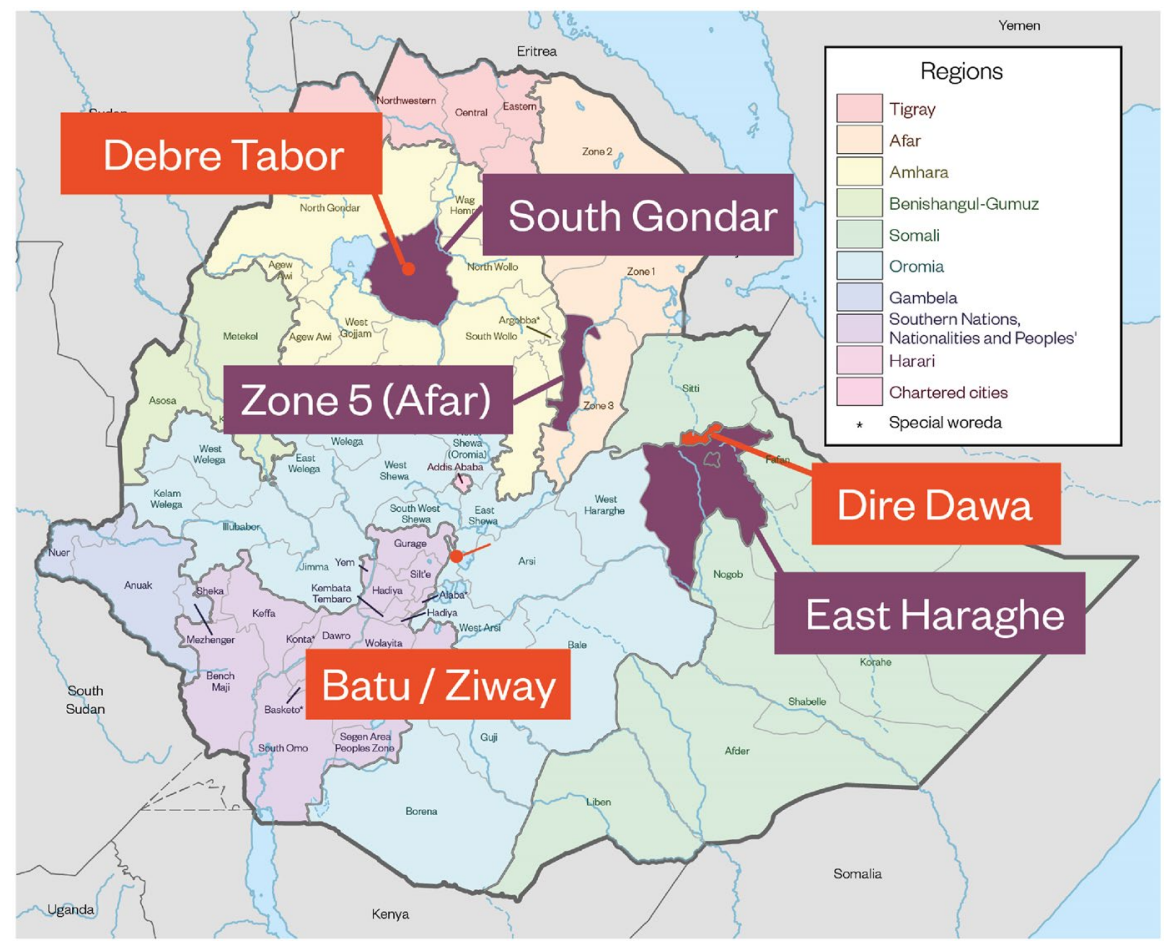

Fig. 2 GAGE research sites in Ethiopia. Rural research sites are indicated in purple, and urban research sites are indicated in orange. Source: Jones et al. 2019

referred to as the "younger" and "older" cohorts in our analysis. Note that $84 \%$ of the younger cohort adolescents were living in rural areas, and the remaining $16 \%$ in urban areas, while the older cohort were living in urban areas only at the time of baseline data collection.

Our analysis, therefore, separately examines adolescents in the younger cohort (aged 10-12 years) and older cohort (aged 15-17 years). There are two main reasons for this. First, the inclusion of younger and older cohorts varies by research site: Debre Tabor and Dire Dawa include adolescents from both younger and older cohorts; East Hararghe, South Gondar (other than Debre Tabor) and Afar sites include only younger cohort adolescents, and the Batu/Ziway sites include only older cohort adolescents. Second, these two age groups are in very different stages of the adolescent life trajectory-particularly with regard to school dropout.

\section{Descriptive Statistics}

The Ethiopian school system consists of eight years of primary education and four years of secondary education (MOE 2015). Primary education is further divided into two cycles of four years: first cycle (grades 1-4) and second cycle (grades 5-8). The appropriate ages for completing the first cycle primary education is 10 years and for 
the second cycle is 14 years. Secondary education is also divided into two cycles: first cycle (grades 9-10) and second cycle (grades 10-12). The appropriate ages of completing the first and second cycle secondary educations are 16 and 18 years, respectively. Because most of the GAGE adolescents are aged 16 or younger, our study of school completion focuses on primary school only; we do not explore secondary school completion (but can explore that using future rounds of GAGE data collection).

\section{Overall Descriptive Statistics}

Table 1 summarizes some general demographic characteristics for the younger and older cohorts by location of residence. Female adolescents constitute $57 \%$ of the younger rural cohort, $50 \%$ of the younger urban cohort, and $51 \%$ of the older urban cohort. ${ }^{5}$ Recent serious illness is reported by $15 \%$ of the younger rural cohort, $25 \%$ of the younger urban cohort, and $23 \%$ of the older urban cohort. The rates of mental distress in the sample are high. ${ }^{6}$ There are substantial differences in the literacy status of household head between rural and urban areas: for the younger rural cohort, $30 \%$ of household heads are literate, while over $70 \%$ of household heads are literate for the urban (younger and older) cohorts.

\section{Younger Cohort}

Looking at the younger cohort (Table 2), 19\% of young rural adolescents are not enrolled in school ( $20 \%$ female, $17 \%$ male) compared to $3 \%$ in urban areas $(5 \%$ female, $1 \%$ male). If the enrolled younger adolescents were progressing as expected in school, they should all have completed first cycle primary education, but only $28 \%$ of rural adolescents and $51 \%$ of urban adolescents had accomplished this. The average highest grade attended by enrolled younger adolescents should have been at least grade 4 if they were progressing as expected; instead, in rural areas was only 3.84 (3.85 females, 3.82 males), while in urban areas it was 4.57 (4.41 females, 4.72 males). Among dropouts, the average highest attended grade was 3.06 in rural areas (3.13 females, 2.93 males) and 2.76 in urban areas (2.93 females, 2.00 males), indicating that most of them left school before completing grade 4 . In fact, $82 \%(81 \%$ females, $82 \%$ males) of dropouts in rural sites and 76\% (71\% females, $100 \%$ males) of the dropouts in urban sites left school before completing the first cycle primary education. Of those enrolled in school at the time of survey, $45 \%$ (44\% females, $46 \%$ males) of rural younger adolescents and 26\% (27\% females, $24 \%$ males) of urban younger adolescents missed one or more school days in the previous two weeks while school was in session. Missed school days accounted for 32\% (33\% females,

\footnotetext{
${ }^{5}$ Females compose nearly $60 \%$ of the rural young cohort research sample due to their relative importance in the programming to be evaluated there as part of the overall GAGE research and due to the oversampling of adolescents who experienced child marriage who are predominantly female.

${ }^{6}$ We create an indicator equal to one if the adolescent indicates any symptoms of mental ill health based on the General Health Questioniare-12 (GHQ-12) (Goldberg and Williams 1988).
} 


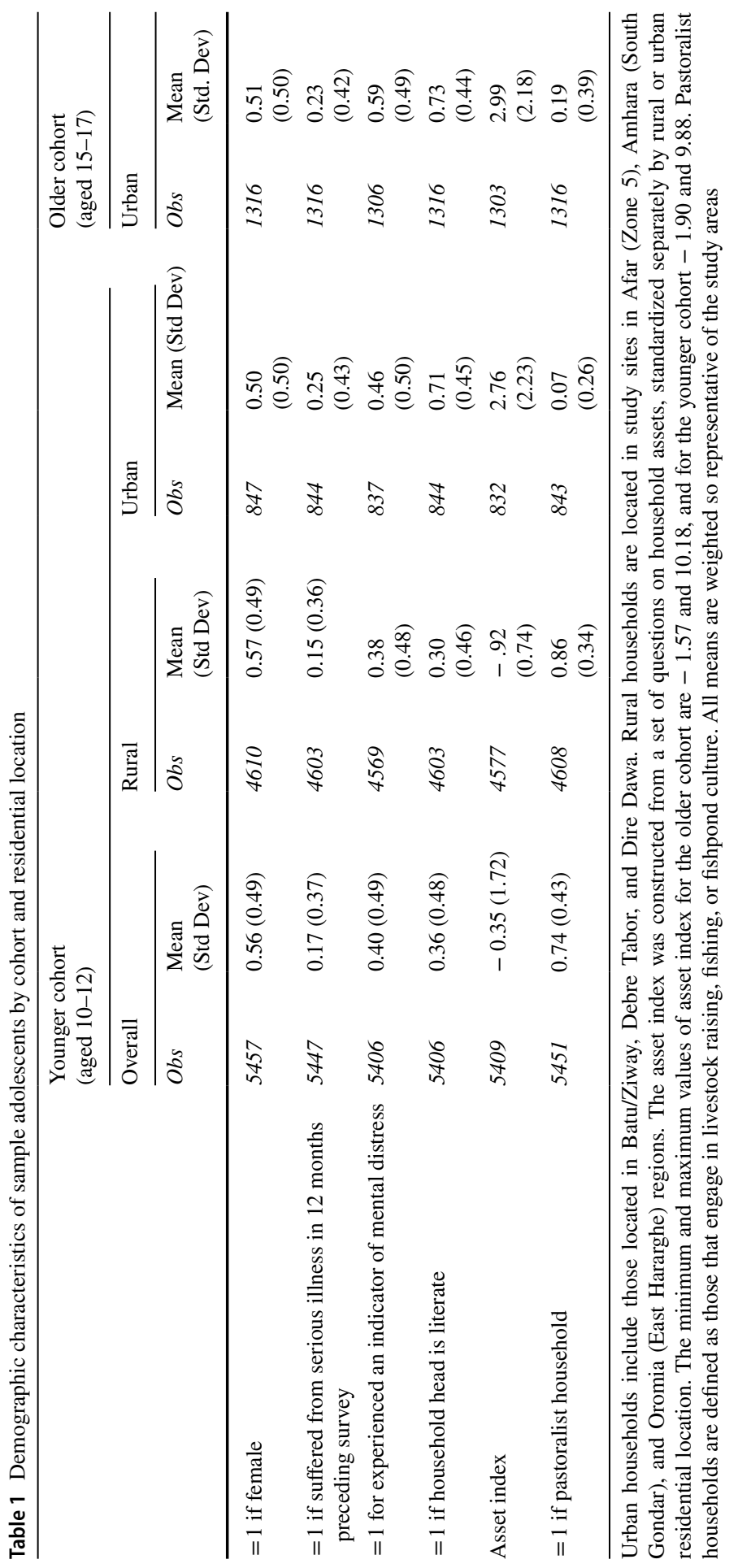




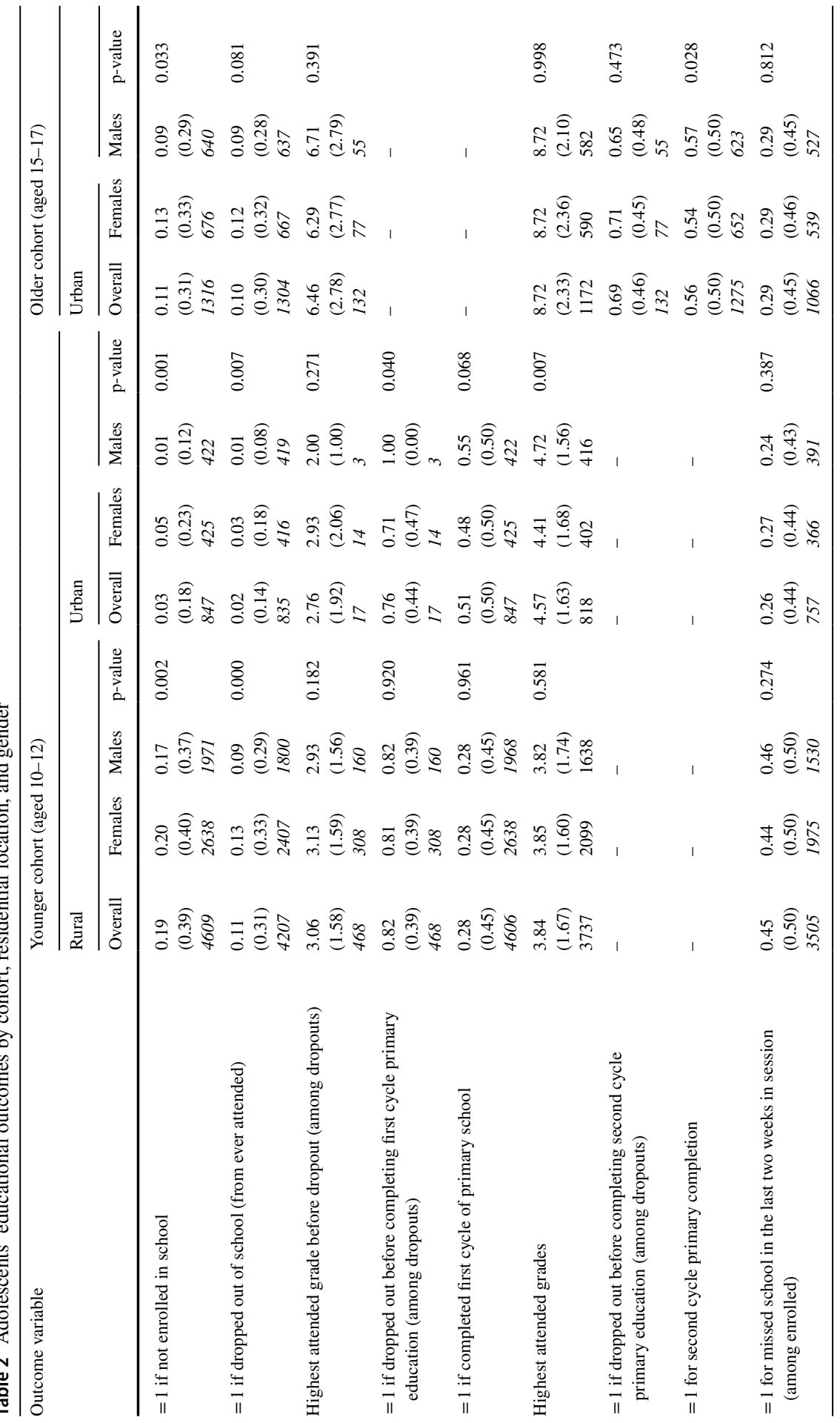

称。 


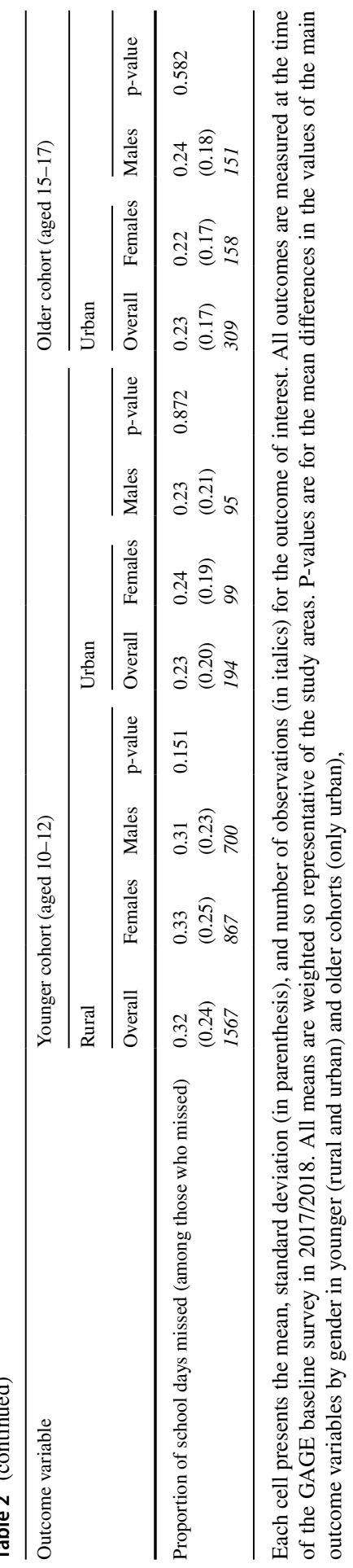


$31 \%$ males) of the total school days during that period among the rural younger adolescent absentees and for 23\% (24\% females, 23\% males) of the total school days during that period among the younger urban adolescent absentees.

\section{Older Cohort (Urban Only)}

Turning to the older (urban only) adolescents (Table 2), we see that approximately $10 \%$ have dropped out of school (12\% for females, $9 \%$ for males). The average highest grade attended by older cohort dropouts is 6.46 (6.29 for females, 6.71 for males), which is 1.54 grades below the required second cycle primary school completion. More than two-thirds of the older urban dropouts (71\% females, $65 \%$ males) left school before completing grade 8 . About $56 \%$ (54\% females, $57 \%$ males) of the older cohort completed the second cycle primary education, with average highest attended grade 8.72 years (same by gender). Of those older adolescents enrolled in school, 29\% (same by gender) missed one or more classes in the previous two school weeks while education was in session. Missed school days accounted for $23 \%$ of the total school days for absentee older cohort adolescents $(22 \%$ for females, $24 \%$ for males).

\section{Reasons for Dropout and Absenteeism}

Surveyed adolescents who dropped out of school were asked to report the main reasons for school dropout (Table 3) and absenteeism (Table 4). Among the younger cohort, the main reasons for dropout include: lack of interest in education for $17 \%$ (19\% females, $11 \%$ males) rural and for $12 \%$ (14\% females, $0 \%$ males) urban individuals; needing to support the household with agricultural activities for $13 \%(11 \%$ females, $16 \%$ males) rural individuals and work (paid or unpaid) for someone outside the household for $12 \%$ (14\% females, $0 \%$ males) urban; own illness or disability for $11 \%$ ( $12 \%$ females, $9 \%$ males) rural and for $18 \%$ (14\% females, $33 \%$ males) urban; lack of parent/guardian support for education for $10 \%$ (12\% females, $6 \%$ males) rural and for $6 \%$ ( $0 \%$ females, $33 \%$ males) urban; and unaffordability of school-related costs (including transport) for $9 \%$ (9\% females, $10 \%$ males) rural and for $12 \%(7 \%$ females, $33 \%$ males) urban.

Among the older urban cohort, the main reasons for dropout include unaffordability of school-related costs for $14 \%$ ( $10 \%$ females, $18 \%$ males), lack of interest in education for $12 \%$ ( $14 \%$ females, $9 \%$ males), being banned for poor academic performance for $11 \%$ ( $14 \%$ females, $7 \%$ males), and own illness for $11 \%$ ( $14 \%$ females, $5 \%$ males).

In terms of absenteeism, an overlapping but slightly different set of reasons dominate, seeming to be clustered much more around work or illness and disability. For the younger cohort, these include: needing to support the household in agricultural activities for $42 \%$ (41\% females, $44 \%$ males) in rural areas and $10 \%$ (11\% females, $8 \%$ males) in urban; own illness for $15 \%$ (18\% females, $12 \%$ males) in rural areas and $43 \%$ (39\% females, $47 \%$ males) in urban; illness or disability of other household 


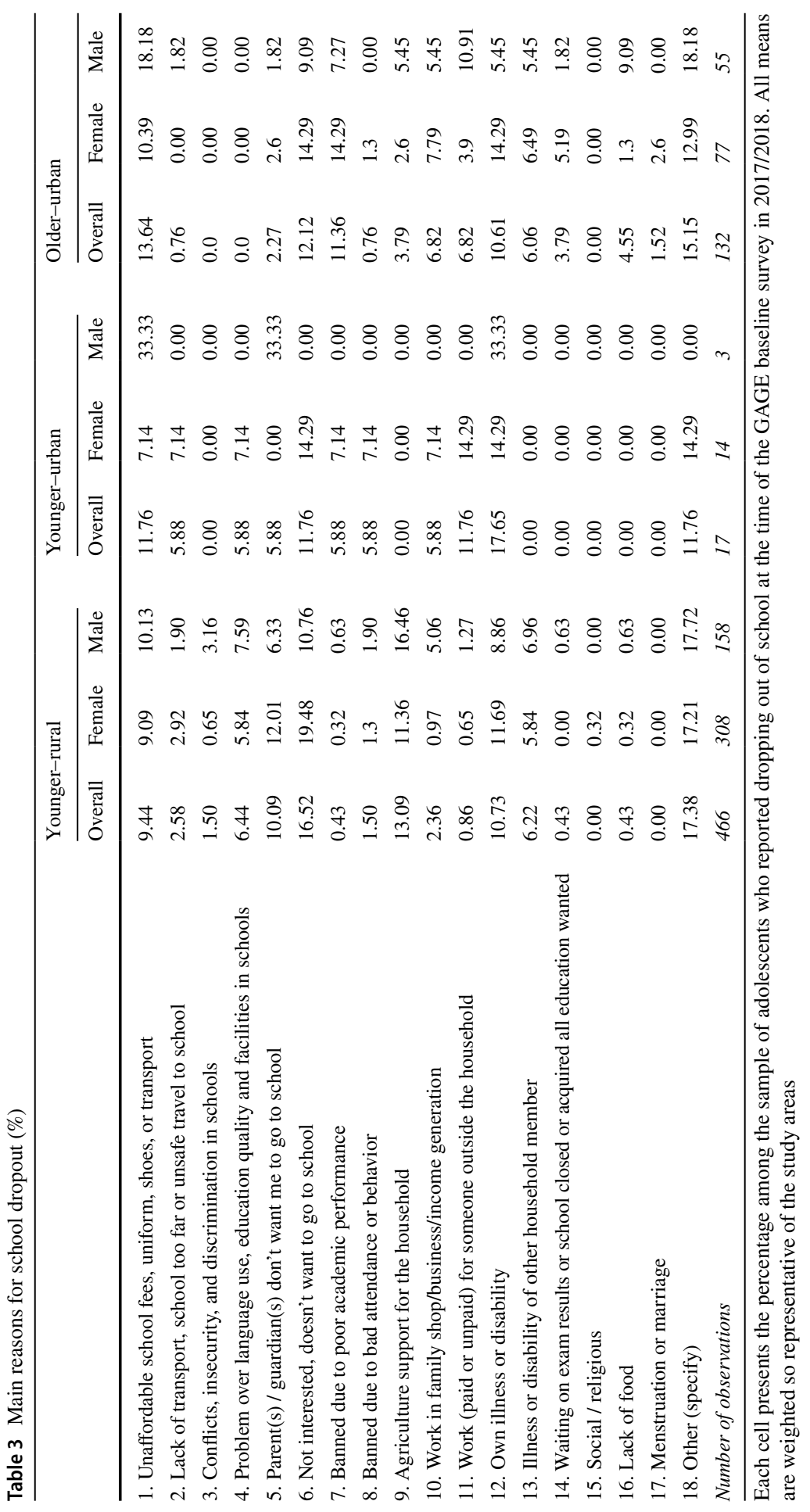


members for $16 \%$ (16\% females, $15 \%$ males) in urban areas; and working in the family business or doing income-generating activity for $11 \%$ (10\% females, $13 \%$ males) in rural areas (Table 4). For the older urban cohort, the main reasons for absence from school are similar-own illness or disability for 31\% (34\% females, $28 \%$ males), $13 \%$ (13\% females, $12 \%$ males) cite having to support the household with agriculture activities and 12\% (17\% females, $7 \%$ males) cite illness of other household members.

\section{Explanatory Variables}

Table 5 presents summary statistics of the main explanatory variables used in our analysis, including measures of adolescent decision-making power within the household, exposure to and/or experience of violence, and paid and unpaid work. Adolescents' say in household decisions related to their own time and life outcomes-our measure of decision-making power, which takes a value of between 0 and $6^{7}$-average 2.77 (2.64 for females, 2.93 for males) among the younger rural cohort, 2.82 (2.68 for females, 2.96 for males) among the younger urban cohort, and 3.34 (3.23 for females, 3.47 for males) among the older urban cohort.

The results for exposure to and/or experience of peer violence indicate the high incidence of the problem among both cohorts: $44 \%$ (38\% females, $51 \%$ males) of younger rural adolescents, $59 \%$ (52\% females, $65 \%$ males) of younger urban adolescents and 51\% (44\% females, 58\% males) of older urban adolescents report having been exposed to or experienced peer violence in the 12 months preceding the survey. This exposure and/or experience of peer violence took place in schools more often than outside of schools; in particular, 32\% (27\%) of rural younger adolescents report being exposed to and/or experiencing violence in school (out of school), 50\% (27\%) of urban younger adolescents, and 38\% (28\%) of older urban adolescents. Though it is important to note that a subset of adolescents were exposed to and/or experienced violence in and out of school-15\% overall (11\% females, $20 \%$ males) in the young rural cohort, $18 \%$ overall (13\% females, $23 \%$ males) in the young urban cohort, and $15 \%$ overall ( $9 \%$ females, $22 \%$ males) in the older urban cohort.

Exposure to and/or experience of violence at home-measured by an indicator variable for experiencing or witnessing violence at home in the 12 months preceding the survey-is also high among all adolescents. 68\% (67\% females, $68 \%$ males) of the younger rural cohort, $62 \%$ (59\% females, $66 \%$ males) of the younger urban cohort, and $59 \%$ (58\% females, $60 \%$ males) of the older urban cohort report exposure to and/or experience of violence at home during the reporting period.

In terms of adolescent work, we explore both paid work and caregiving. Only 5\% of younger rural adolescents ( $5 \%$ females, $6 \%$ males), report engaging in paid work in the 12 months preceding the survey (and just 3\% of younger urban adolescents),

\footnotetext{
7 The items included in this index are own say in: time spent helping around the house, time spent in leisure, educational attainment, when to marry, marital partner, and friends.
} 


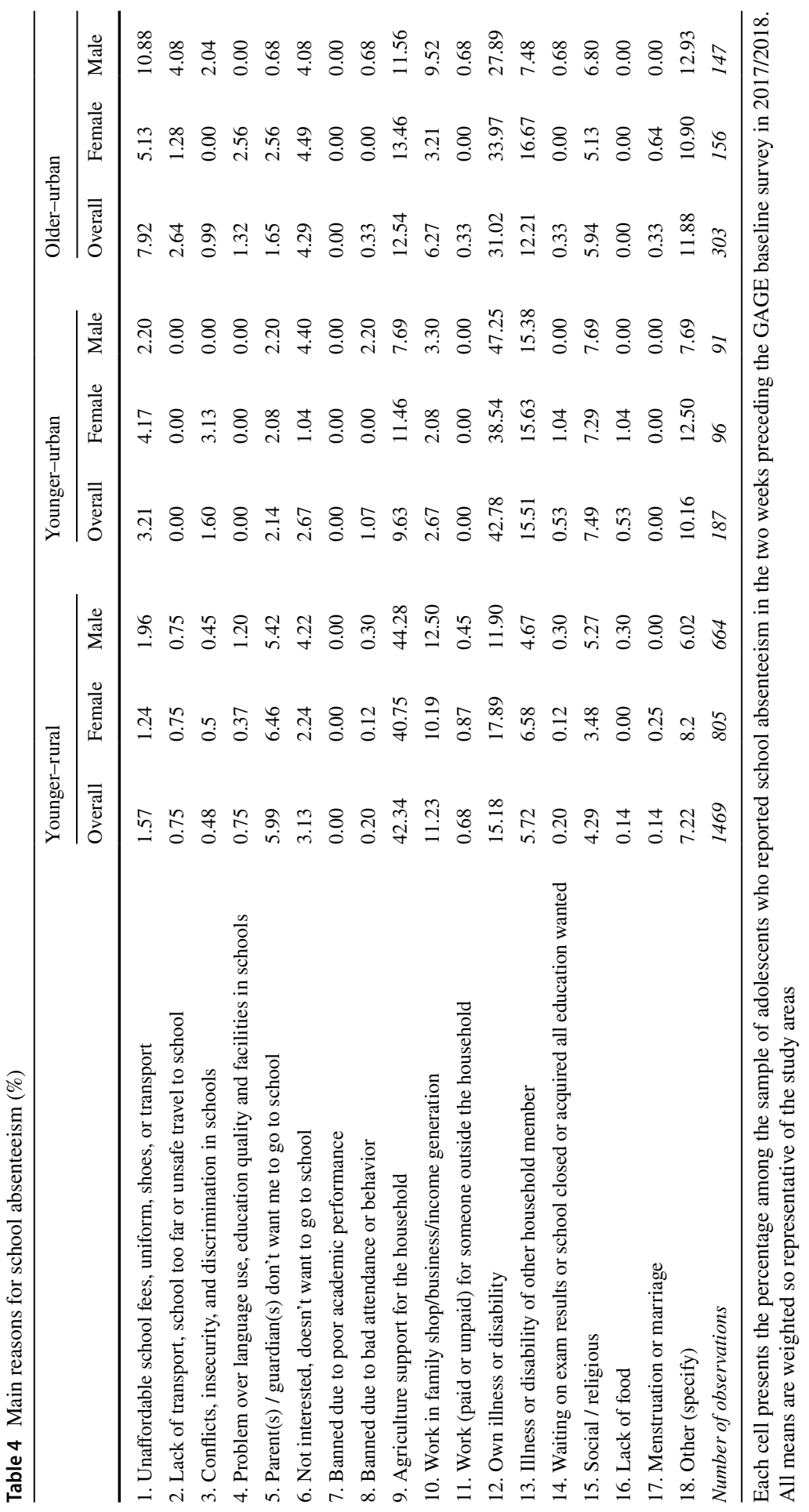


compared to $21 \%$ of older urban adolescents (14\% females, $28 \%$ males). Instead, caregiving responsibilities are more likely for younger adolescents, with 35\% (44\% females, 24\% males) of rural adolescents and 27\% (29\% females, 25\% males) of urban adolescents engaging in caregiving during the reporting period, compared to just $10 \%$ of older urban adolescents (14\% females, $5 \%$ males).

\section{Regression Results}

\section{School Dropout}

Table 6 presents the results on school dropout, including indicators for whether the adolescent dropped out of school at some point (by cohort and overall, columns 1-3), dropped out of school before completing grade 4 (younger cohort, column 4), or dropped out of school before completing grade 8 (older cohort, column 5). For the grade-specific dropout measures, the sample was restricted to students who had dropped out at some point.

Looking first at adolescent decision-making power in the household, we see that it is strongly negatively associated with school dropout for both the younger (0.8 percentage points (p.p.), $p<0.05)$ and older cohorts $(2.2$ p.p., $p<0.01)$, although magnitudes are small. Exposure to and/or experience of peer violence (outside school) is positively associated with school dropout, and this is large and significant among the older cohort (6.5 p.p., $p<0.05)$. Exposure to and/or experiencing violence at home, on the other hand, is significantly negative across both cohorts (2.5 p.p., $p<0.05$ for younger adolescents; 4.0 p.p., $p<0.05$ for older adolescents). These findings should be interpreted with caution, as they could reflect reverse causality, whereby dropping out of school reduces stress and conflict in the household.

Performing paid work in the 12 months preceding the survey is positively and significantly associated with school dropout. Engaging in paid work is associated with a 9.7 p.p. $(p<0.01)$ increase in school dropout among the younger cohort, and an 18.9 p.p. $(p<0.01)$ increase in dropout among the older urban cohort. Although performing caregiving is only marginally statistically significant for the younger cohort, results across both cohorts suggest a positive relationship between caregiving and school dropout (column 3, 2.0 p.p., $p<0.05$ ). These results suggest that demand for adolescents to engage in paid work or caregiving is a serious factor in school dropout.

There are a few important findings to highlight from the covariates. Females are significantly more likely to be out of school in both cohorts (4.5 p.p. for younger and 6.1 p.p. for older adolescents). Among younger adolescents, urban adolescents are 66 p.p. $(p<0.01)$ less likely to be out of school than rural adolescents. There is also some evidence that the household head's literacy, household assets, and household service access are all negatively associated with dropout. The estimates on residing in an urban area and access to services likely reflect the importance of access to nearby and quality schools in deterring dropout. 


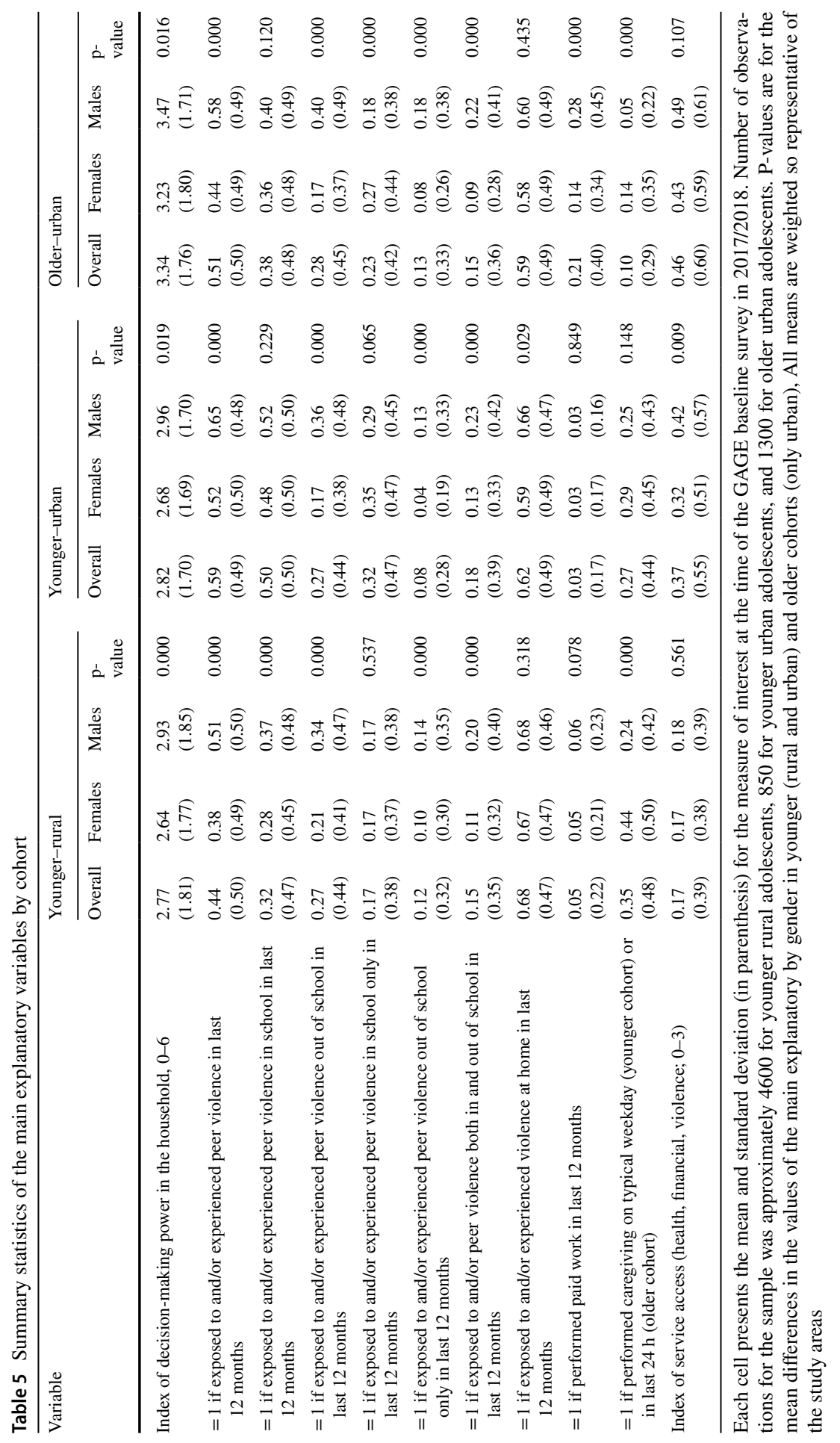




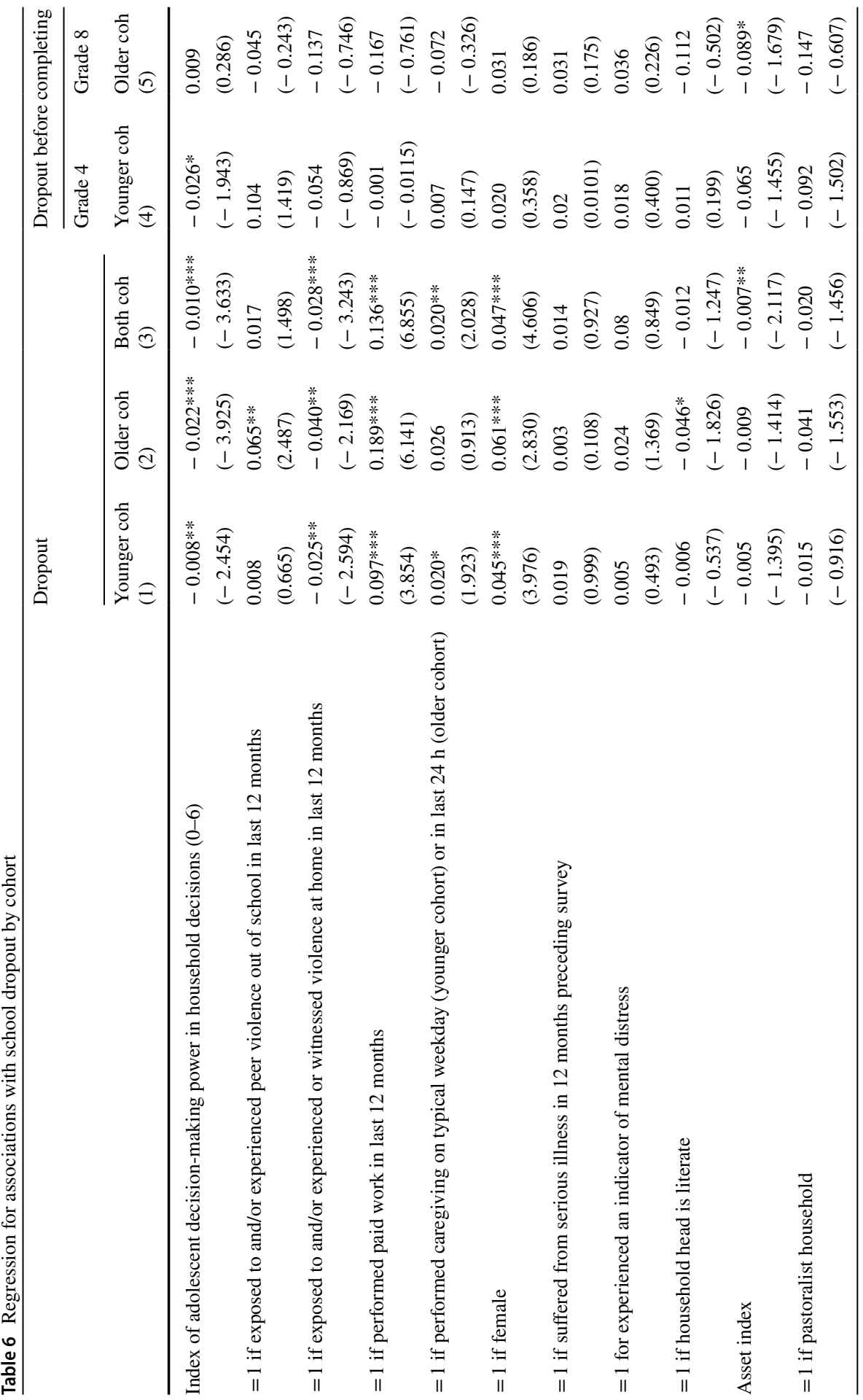

迕 


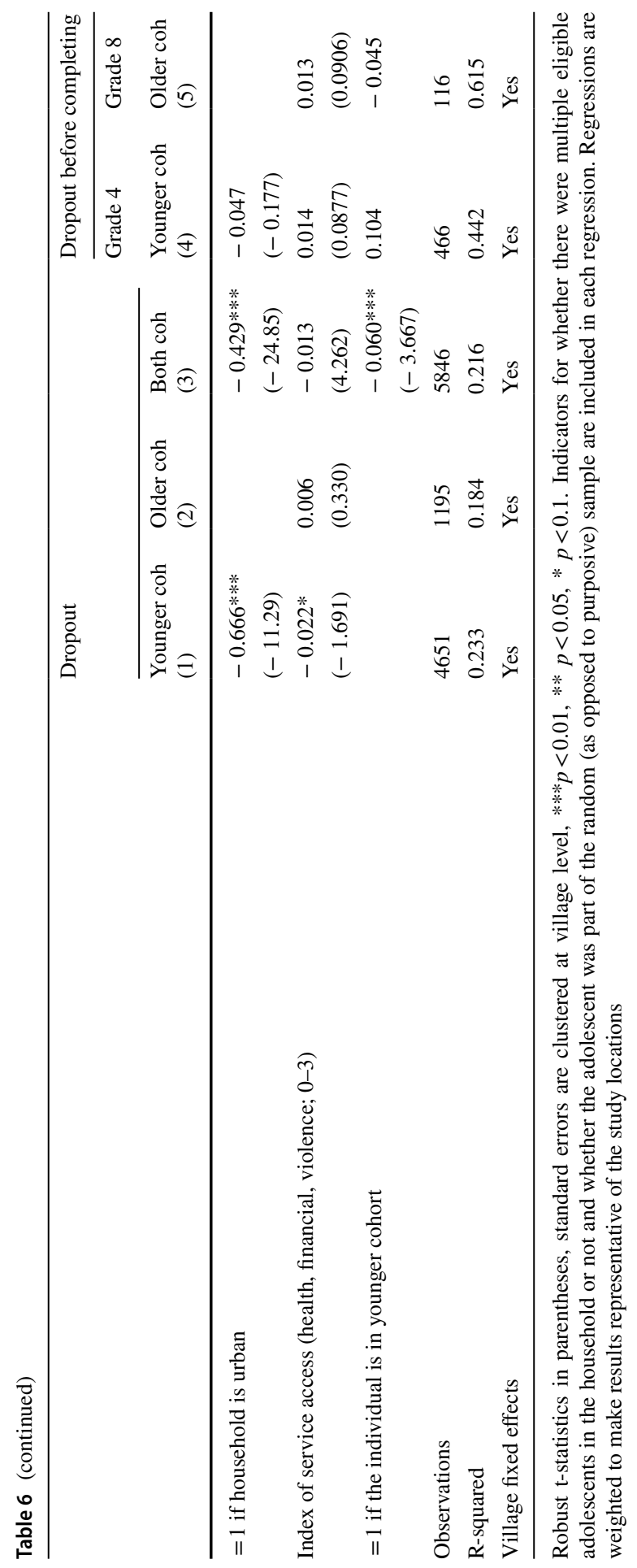


When we look at grade-specific dropout rates (Table 6, columns 4 and 5), we find limited significant associations, at least partially due to the reduced sample size in these regressions. Yet, most coefficients go in the expected direction. In particular, we find suggestive evidence among the younger cohort of dropouts that adolescent decision-making power in the household is associated with lower dropout prior to completing grade 4 (2.5 p.p., $p<0.1$ ), and among the older cohort that wealth protects from dropout before completing grade 8 (8.9 p.p., $p<0.1$ ).

Table 7 repeats the regressions presented in Table 6, columns 1 and 2, but this time with results disaggregated by gender. We find that many, but not all, of the important associations uncovered in Table 6 are driven by female adolescents, with coefficients both larger and more significant. Adolescent decision-making power in the household is found to have a significant negative association with dropout of females for both the younger (1.1 p.p., $p<0.01)$ and older cohorts (2.9 p.p., $p<0.01)$; the relationship between adolescent decision-making power and dropout is insignificant for males in both cohorts. Exposure to and/or experiencing of peer violence (outside school) is positive and significant in the older cohort for both females (9.7 p.p., $p<0.05$ ) and males (4.8 p.p., $p<0.1$ ). Exposure to and/or experiencing of violence at home is significantly negative among both younger cohort females (3.3 p.p., $p<0.05)$ and males (2.8 p.p., $p<0.1)$.

Engaging in paid work is the only determinant we explore that is consistently statistically significant across both genders and age cohorts. It is associated with dropout of both females in the younger cohort (13.1 p.p., $p<0.01)$ and older cohort $(19.5$ p.p., $p<0.01)$ and males in the younger cohort (6.2 p.p., $p<0.1)$ and older cohort (20 p.p., $p<0.01$ ). These results suggest that demand for adolescents to engage in paid work is a serious factor in school dropout for females in both cohorts and for males (especially in the older cohort). ${ }^{8}$

\section{School Absenteeism}

Table 8 provides a clear picture of the importance of adolescent decision-making power, exposure to, and/or experience of violence and child work in adolescents' school absenteeism, overall (columns 5 and 6), and by cohort (columns 1-4). For the younger cohort, adolescent decision-making power in the household is negative and statistically significant with a one unit increase in the index of decision-making power decreasing absenteeism by 0.46 p.p. $(p<0.1)$. Exposure to and/or experience of peer violence is significantly associated with a greater likelihood of school absenteeism. Exposure to and/or experience of any peer violence in the past 12 months is associated with a 2.5 p.p. $(p<0.01)$ increase in school absenteeism, with all three disaggregated indicators of peer violence (in school, out of school, and in and out of school) also positive and statistically significant. The coefficients on caregiving are also significant, suggesting that engaging in care work increases absenteeism by 2.9 p.p. $(p<0.01)$.

\footnotetext{
${ }^{8}$ Findings for dropout before completing grade 4 (for younger cohort) and grade 8 (for older cohort) by gender are not shown due to small sample sizes.
} 


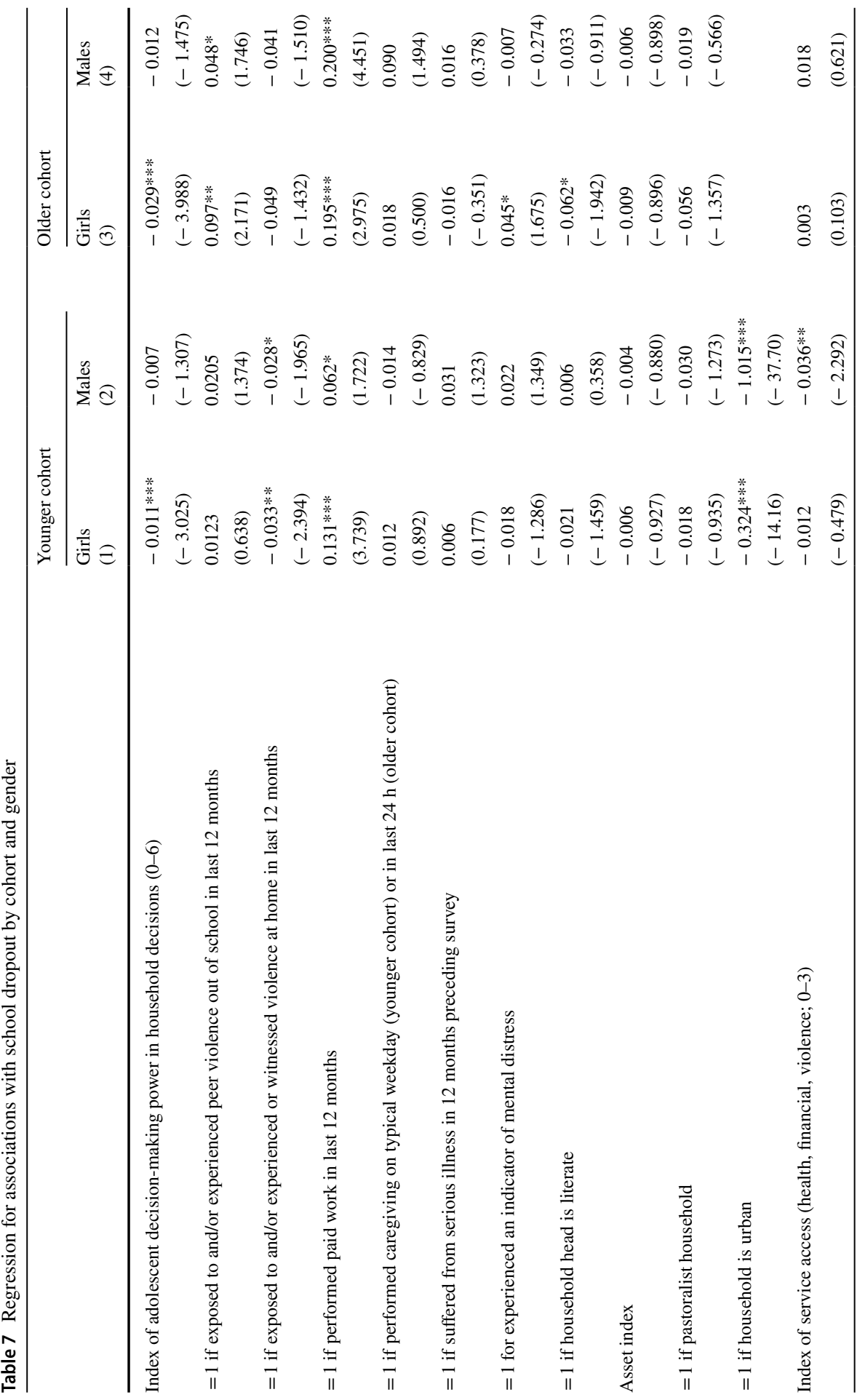




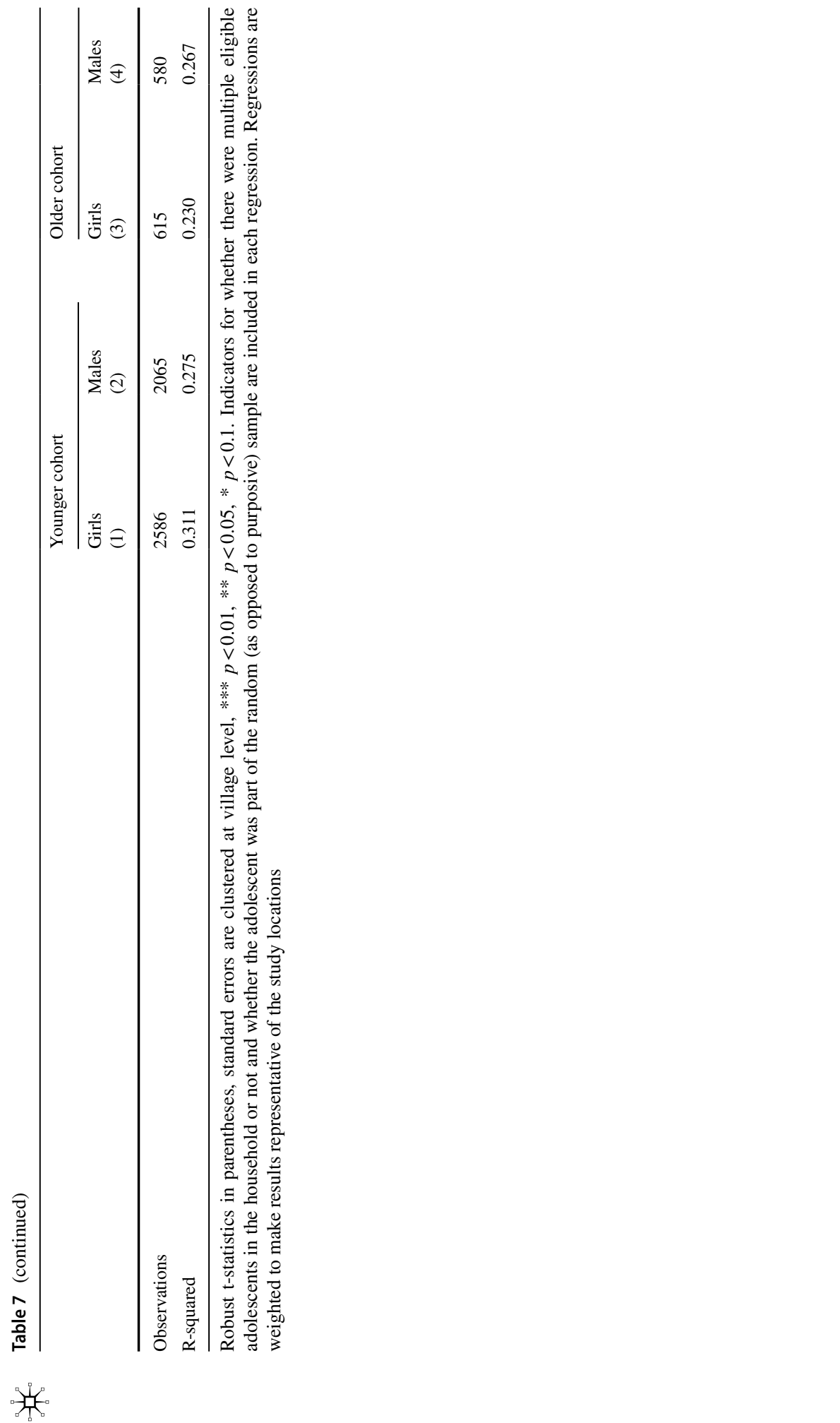




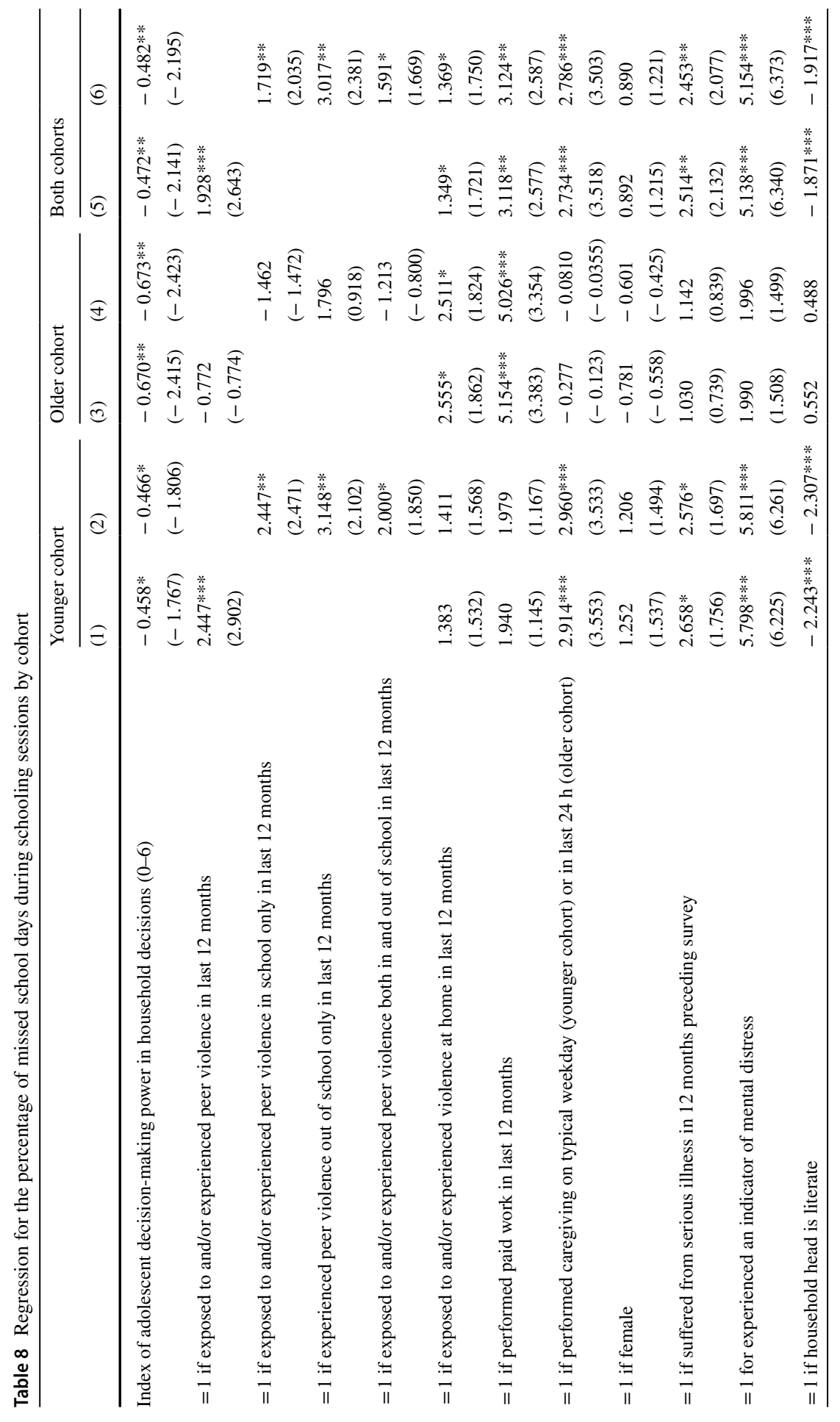

就 


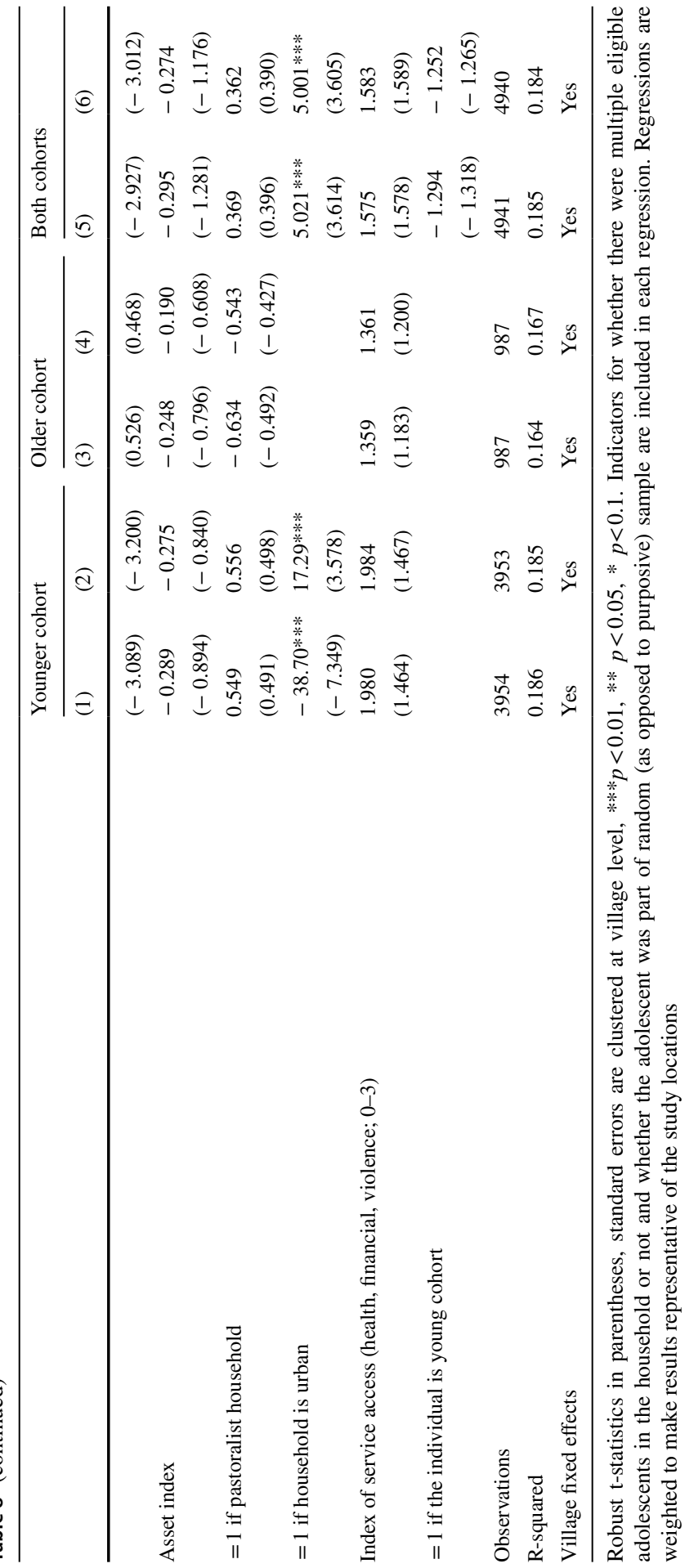

起。 
For the older cohort, adolescent decision-making power is negative and statistically significant with a one unit increase in decision-making power decreasing absenteeism by 0.67 p.p. $(p<0.05)$. Home violence as opposed to peer violence is positively and significantly associated with absenteeism, exposure to and/or experience of violence at home is associated with a 2.6 p.p. increase in absenteeism. Paid work is also strongly associated with absenteeism: participating in paid work is associated with a 5.2 p.p. $(p<0.01)$ increase in absenteeism. It is important to highlight the changing dynamics in the type of violence and type of work associated with absenteeism as adolescents get older.

Estimation of absenteeism for each of the two cohorts broken out by gender is reported in Table 9. Adolescent decision-making power in the household is negative and marginally statistically significant for males in the younger cohort and females in the older cohort. Exposure to and/or experience of peer violence is significantly associated with a greater likelihood of school absenteeism for both females (2.57 p.p., $p<0.05)$ and males $(2.28$ p.p., $p<0.1)$ in the younger cohort, and, at least for girls, this appears to be mainly driven by peer violence happening in school. In contrast, exposure to and/or experience of home violence has a significantly positive association with absenteeism of boys in the younger cohort $(2.9$ p.p., $p<0.05)$ and the older cohort (3.9 p.p., $p<0.1$ ), but has no significant association with dropout of females in either cohort.

Paid work is strongly associated with absenteeism of females (6 p.p., $p<0.05)$ and males $(5.1$ p.p., $p<0.01)$ in the older cohort, while caregiving is significantly associated with a higher percentage of females' absenteeism (3.7 p.p., $p<0.01)$ for the younger cohort.

\section{First and second cycle primary education completion}

Table 10 presents the regression results for the determinants of first cycle primary completion for the younger cohort (columns 1-2) and second cycle primary completion for the older cohort (columns 3-4). ${ }^{9}$ For both cohorts we see that adolescent decision-making power matters, being associated with a 1.8 p.p. $(p<0.01)$ increase in first cycle primary completion for the younger cohort and a 2.3 p.p. $(p<0.01)$ increase in secondary school attendance for the older urban cohort. We find no association between exposure to and/or experience of violence and second cycle primary completion, but peer violence out of school and home violence are negatively associated with first cycle primary school completion-with respective effects of 4.9 p.p. $(p<0.05)$ and 3.4 p.p. $(p<0.05)$. For second cycle completion, paid work is extremely important, associated with an 8.1 p.p. decrease $(p<0.05)$.

From the other correlates, the asset index is positive and significant for both age cohorts. A one standard deviation increase in the household's asset index

\footnotetext{
9 Since grade completion data are unavailable and it is only those who completed the second cycle primary education that attend secondary education, the indicator for secondary school attendance is used as a proxy for second cycle primary completion of older cohorts.
} 


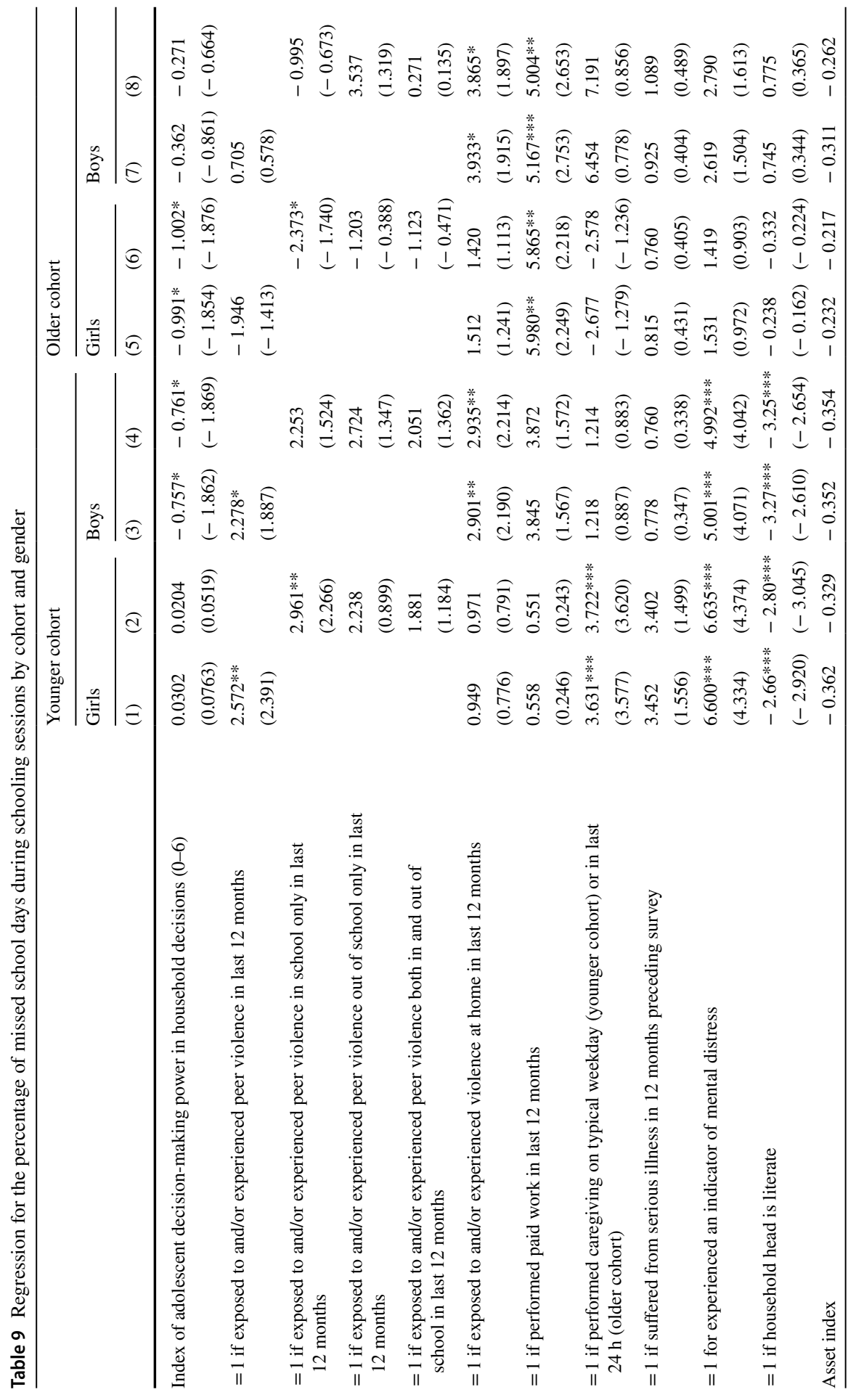

然 


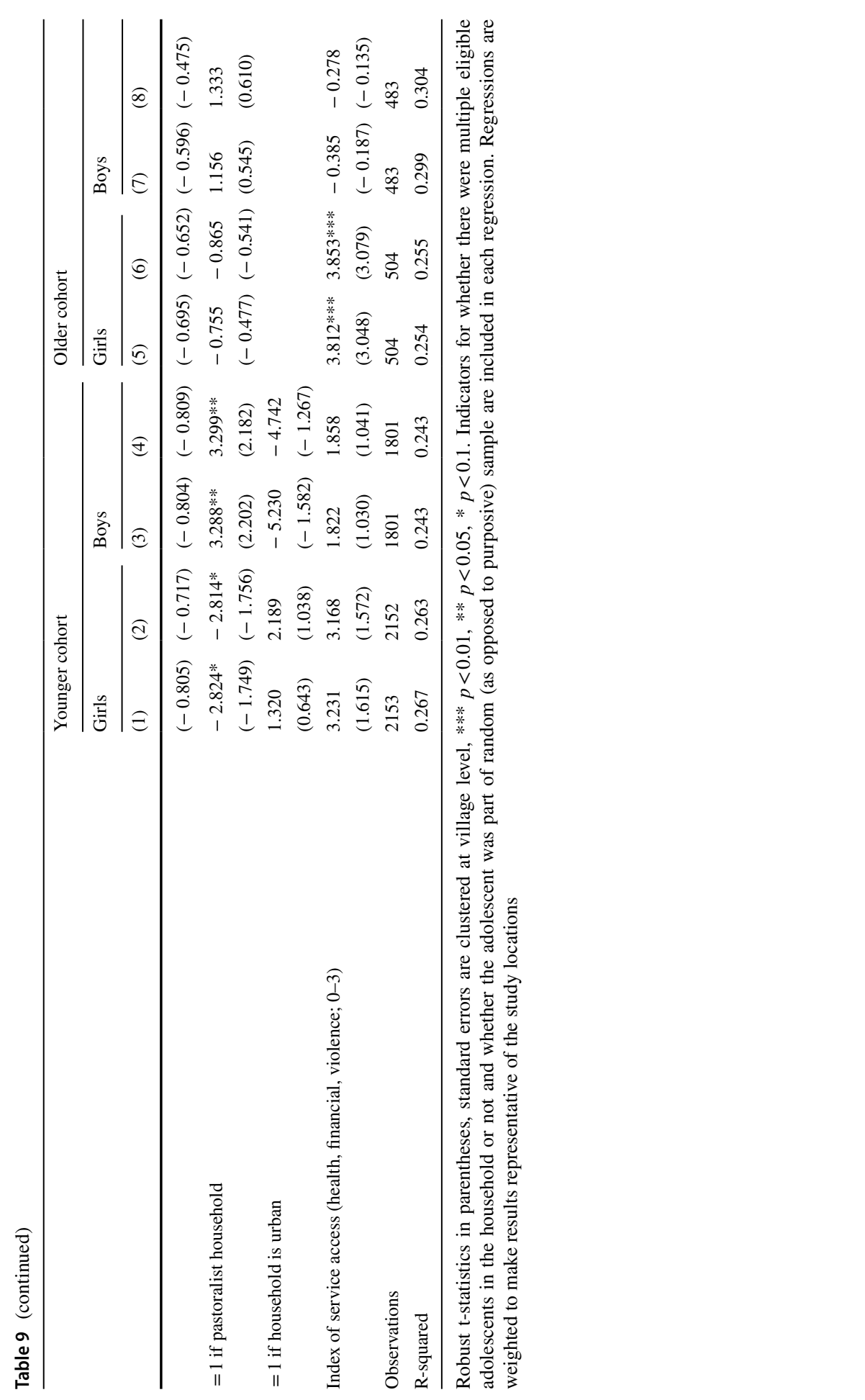




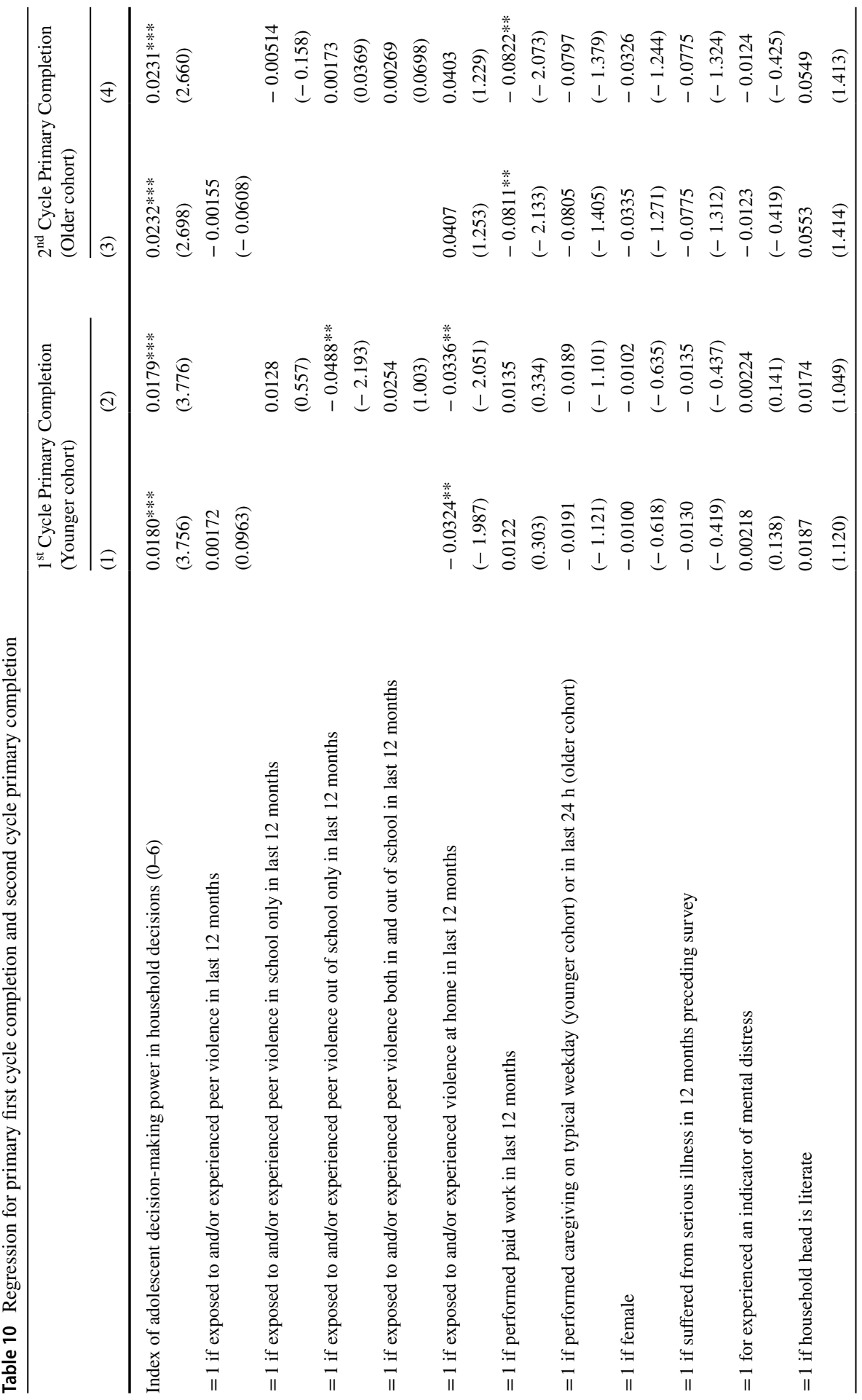

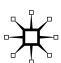




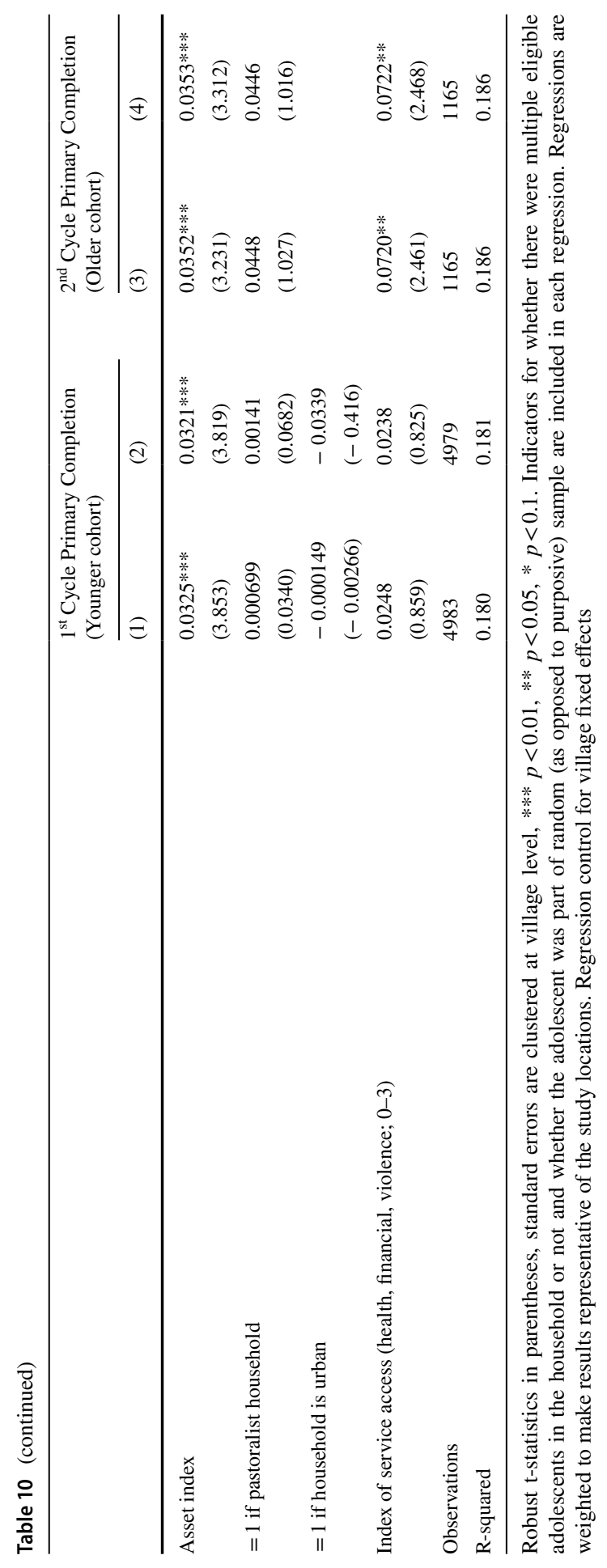


is associated with a 3.2 p.p. $(p<0.01)$ increase in grade 4 completion among the younger cohort and a 3.4 p.p. $(p<0.01)$ increase in attending secondary school among the older cohort. The index for access to services is positive and significant in the regression for secondary school attendance, with a one standard deviation increase in the service access index associated with a 7.2 p.p. higher probability of second cycle primary completion. Interestingly, the urban indicator is not associated with first cycle primary completion.

The regressions of first and second cycles primary education by cohort and gender of the adolescent are reported in Table 11. Adolescent decision-making power is found to be significantly positive for females in both younger $(2.2$ p.p., $p<0.01)$ and older cohorts (2.5 p.p., $p<0.1)$ and for males in younger cohorts $(1.6$ p.p., $p<0.05)$. Exposure to and/or experience of peer violence is significantly negative for males in older cohort (7.2 p.p., $p<0.1)$ and from its disaggregated indicators exposure to and/or experience of peer violence (outside school) and peer violence (both inside and outside school) are significantly negative for females in younger cohort and males in older cohort, respectively. Exposure to and/or experience of home violence is significantly negatively associated with first cycle primary completion for females (5.0 p.p., $p<0.05$ ). From the other covariates, the asset index is significantly associated with primary school completions of females and males in both cohorts and in the younger cohort residency in urban areas is also significantly positive for females as well as males.

\section{Discussion of Findings}

This section provides further discussion of the main findings, situating them in the existing empirical evidence, and discusses limitations of the analysis.

\section{Adolescent Decision-Making Powers in the Household}

Our findings suggest that adolescent boys and girls with more decision-making power in the household have better educational outcomes. This result suggests that adolescent autonomy in education is indispensable in completing primary education. When adolescents' voices are heard, they prioritize their education by attending classes regularly and by spending several hours in studying and completing tasks such as homework. After uncovering the negative effects of child marriage on females' secondary school enrollment and completion, Wodon et al. (2016) suggested that females' agency (such as having a say in timing of marriage) could improve secondary school enrollment and completion by delaying child marriage. The result suggests that engaging parents to empower adolescents and give them a say in decision-making (thereby increasing their agency) could be instrumental in enhancing children's educational attainment. Adolescent decision-making power, however, does not necessarily imply better educational attainment as it is possible that in some contexts adolescents with better decision-making power might prioritize getting married or paid jobs over their education. 


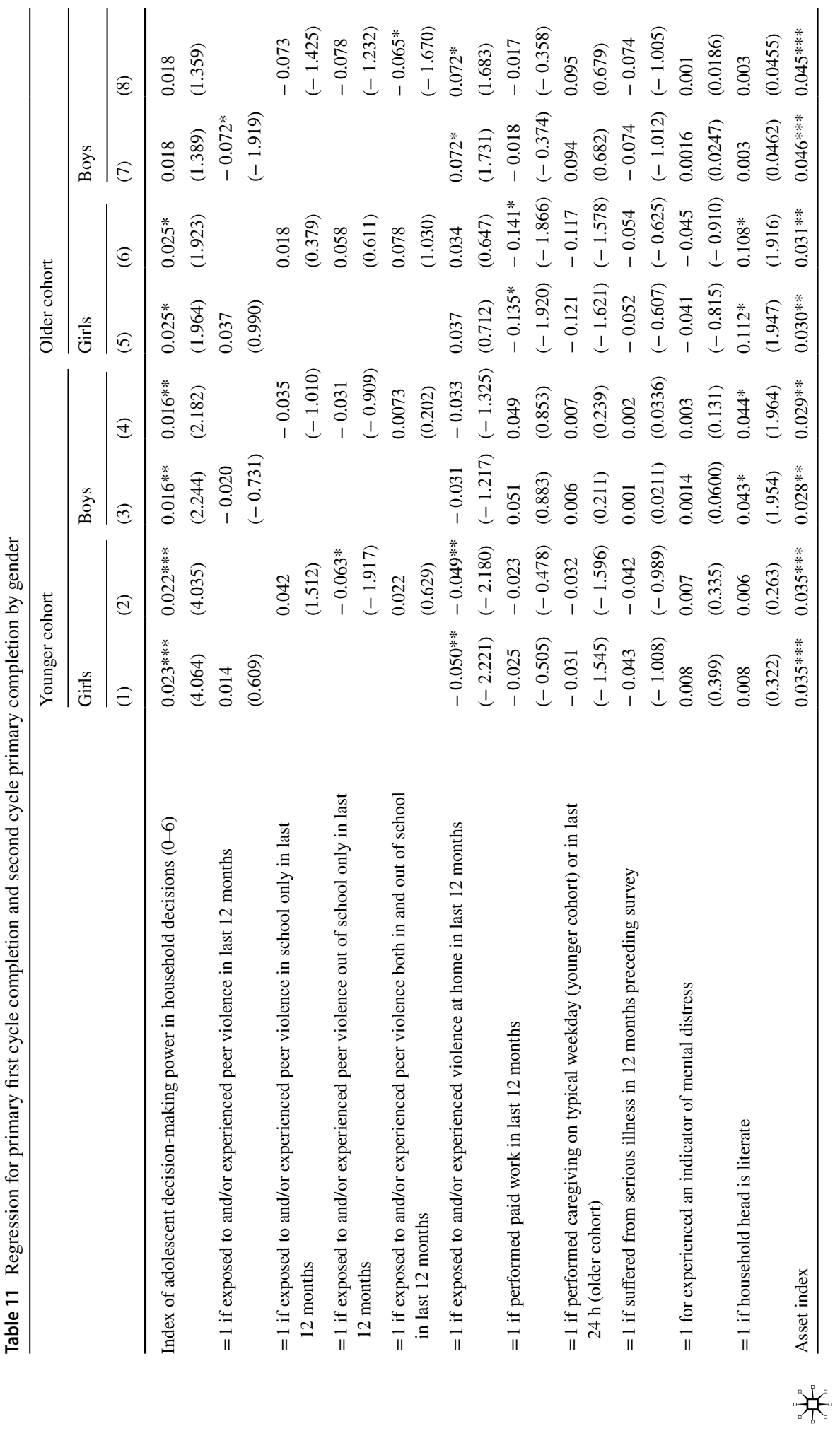




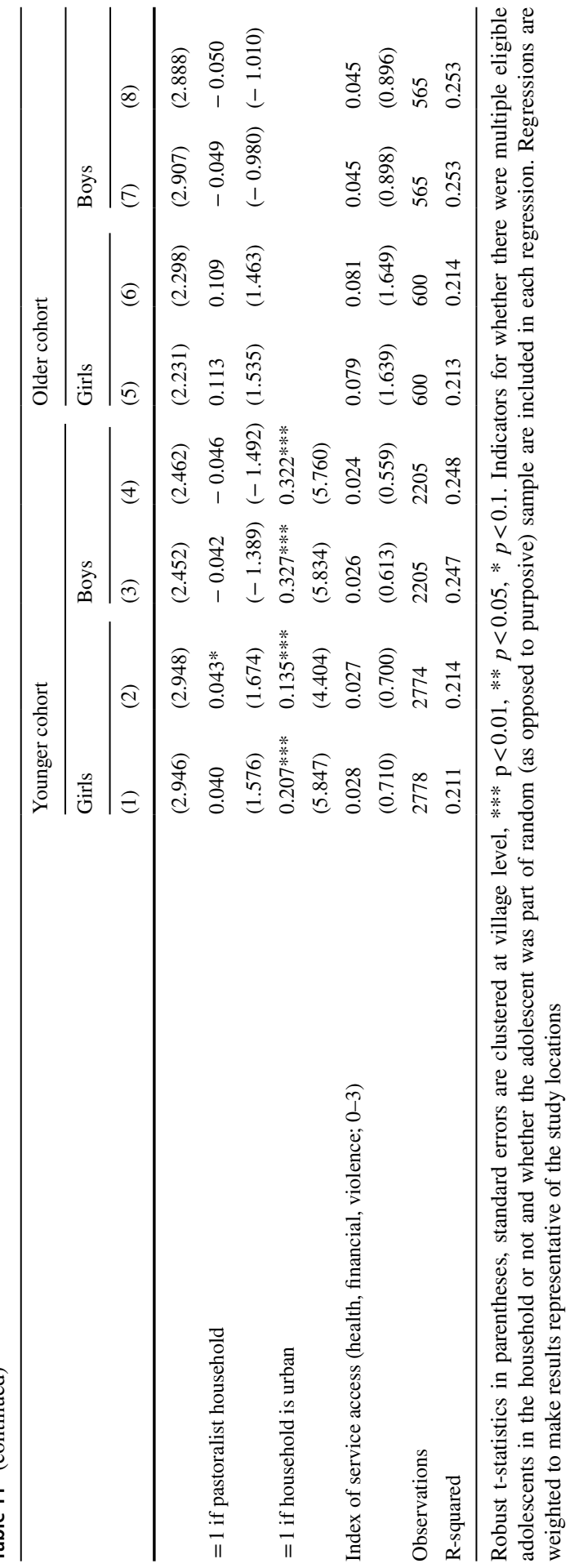

起。 


\section{Exposure to and/or Experience of Violence (Peer and Home)}

The study shows a significant negative relationship between exposure to and/or experience of violence (both peer and home) and adolescents' schooling outcomes in Ethiopia. These findings are consistent with other empirical evidence. Psaki et al. (2017) found a positive association of domestic (home) violence with higher school absenteeism for males and subsequent dropout of females using longitudinal data from adolescents in rural schools in Malawi. Abuya et al. (2013) found that family violence such as violence to mothers drives dropout of children from school. With regard to peer violence, Pilley (2017), using a sample of 443 children from six primary schools in Johannesburg, showed that those who reported being bullied by their peers scored lower in literacy tests than the unaffected. Kibriya et al. (2015) uncovered the negative effects of being bullied on the academic performance of grade 8 students in Ghana and Makafane (2019) showed that bullying leads to poor educational performance such as frequent school absenteeism, dropout, and lower scores in the exams of high school students in Lesotho. Dunne et al., (2013) also showed larger absenteeism of senior high school students in Ghana due to bullying. The growing body of evidence on the importance of peer and home violence in driving education outcomes, further supported by this analysis, suggests that increased attention is needed to address violence as an impediment to primary school class attendance, grade progression, and school completion of adolescents in Ethiopian schools.

\section{Paid Work and Unpaid Care Participation of Adolescents}

The descriptive statistics show that even though both cohorts are involved in work, the type of works varies considerably, with the younger cohort largely involved in domestic chores and the older cohort mainly engaged in income-generating activities. Our analysis finds that domestic chores (for younger adolescents) and paid work (for older adolescents) decrease adolescents' educational outcomes. Our findings on paid and unpaid care giving is consistent with the evidence of Putnick and Bornstein (2015) who obtain negative relationships of working outside home, family work, as well as household chores with school enrollment of 7-14 year old children in 30 LMICs. Their findings further shows that the inverse relationships are more consistent for domestic work and household chores than the work outside home. Our finding of the negative relationship between paid work (mostly work outside home) and adolescents' educational outcomes is consistent with the findings of other empirical studies such as Woldehanna and Hagos (2015) and Getnet and Beliyu (2012) in Ethiopia, and Bai and Wang (2020) in India, and Gibbons et al., (2015) who provided an inverse relationship of child labor and school attendance by employing data from 18 African countries. 


\section{Covariates}

Our findings also align with the literature in terms of the role of demographics in influencing adolescents' educational outcomes. We found that females have worse schooling outcomes, echoing studies such as Sabates et al. (2013), which found greater incidence of school dropout among females compared to males in Bangladesh. Experiencing illness and mental distress are found to be negatively associated with school retention. Consistent evidence is found from other studies. King et al. (2015), for example, find that in Kenya, reported illness arising from malaria and menstruation are factors underlying absenteeism from primary schools. And Sahin et al. (2016) find that illness is the most important determinant of school absenteeism in Turkey.

Literacy status of the household head is positively associated with educational outcomes, potentially illustrating the foresightedness of educated parents regarding the benefits of educating their children or capturing the fact that literate household heads are more likely to be wealthy and live in urban areas. Our result for parent literacy is consistent with other empirical findings such as Okumu et al. (2008), who found a significant inverse relationship between dropout from primary school and parental education in Uganda. Boualaphet and Goto (2020) also showed a significant role of mother's education in reducing dropout of female students in the case of Lao People's Democratic Republic (PDR). Wealth, as measured by an asset index, is also associated with better educational outcomes, highlighting that poorer households tend to withdraw their children from school if they need their services or cannot afford school-related costs. The evidence on the asset index is also consistent with the findings of Sabates et al. (2013), who uncovered a significant inverse relationship between high income status of households and school dropout in Bangladesh.

Community-level characteristics, particularly urban residence, is an extremely important factor in educational outcomes. Studies by Bergmann (1996) and Ziyn (2012) also found greater incidence of school dropout in rural areas arising from poor quality of schooling in such areas. Boualaphet and Goto (2020) also showed that female students in remote areas tend to drop out of school more often than those in urban areas in Lao PDR. Lower school attendance of children in rural areas of Solomon Islands and Vanuatu was also reported by Pooso and Feeny (2016).

\section{Limitations}

Our analysis has a number of important limitations, and we highlight three here. First, it is a cross-sectional analysis and thus findings should be interpreted as correlations and not as causal. Second, we use relatively simple quantitative regression models (LPM and OLS) to assist with ease of interpretation and results may differ with more complicated models. Third, some conceptual variables are challenging to capture empirically (e.g., adolescent decision-making in the household), and our analysis is constrained by what can be constructed with the data. Findings and subsequent policy implications should be interpreted with these limitations in mind. 


\section{Conclusion and Policy Implications}

Our findings suggest that adolescent decision-making power in the household, exposure and/or experience to peer and household violence, and paid and unpaid work all play a significant role in adolescents' educational outcomes in Ethiopia, alongside other demographic, household characteristics, and locations such as gender, health, wealth, and urban residence. While adolescent decision-making power in the household is associated with lower dropout and absenteeism and higher grade completion in both younger and older cohorts, the associations with exposure to and/or experience of violence and child work vary by cohort.

Exposure to and/or experience of peer violence is associated with higher dropout in older cohorts and higher absenteeism in younger cohorts, and lower first cycle primary school competition in the younger cohort. Exposure to and/or experience of home violence, on the other hand, is associated with higher absenteeism in the older cohort and lower first cycle primary school completion in the younger cohort. Participation in paid work is associated with higher dropout (in both cohorts) and absenteeism (in the older cohort only) and lower second cycle primary completion (in the older cohort). Performing unpaid caregiving activities is associated with higher dropout and absenteeism in the younger cohort only.

Further investigation of these relationships split apart by gender within cohorts shows that adolescent decision-making power in the household is negatively associated with dropout only for females (in both cohorts) and absenteeism for males in the younger cohort and females in the older cohort showing that decision-making power of the adolescent is more binding for girls' absenteeism than for boys. The association of adolescent decision-making power in the household with the first and second cycle primary school completion is significantly positive for females in both cohorts, but for males only in the younger cohort. The results suggest that enhancing adolescent decision-making power in the household is likely to be particularly effective in improving the education outcome of adolescent females. Exposure to and/or experience of peer violence is associated with higher absenteeism for both females and males in the younger cohort, while exposure to and/or experience of violence at home is found to be significantly positive only for absenteeism of males in both cohorts. Engaging in paid work, on the other hand, is associated with dropout of both females and males in both cohorts. This finding highlights the importance of tackling child labor in improving education outcomes for adolescents of all ages and both genders.

Ultimately, these findings suggest that a concerted effort is needed at the household, school, and community levels to foster a suitable learning environment for Ethiopian adolescents, so that the SDGs' call to leave no child behind by 2030 can move closer to becoming a reality. Some possible program and policy actions that may improve education outcomes in Ethiopia include the following:

- Parenting programs which enhance the decision-making power of adolescents, particularly girls, and help ensure enough time is spent on education-related outcomes and that violence is reduced. A recent GAGE study by Marcus et al. 
(2020) in LMICs shows that parenting programs which enhance sharing information and practicing of new communication skills between caregivers and children are effective in preventing physical and emotional violence toward adolescents.

- Conduct community awareness programs that aim to reduce the exposure to and/ or experience of peer violence among adolescents.

- Implement school-based programs that aim to reduce the exposure to and/or experience of peer violence within schools and promote behaviors that build harmonious relationships between students.

- Revisit public support programs and conditional cash transfers by considering the introduction of children's school enrollment as a precondition for eligibility to the productive safety net programs. This could reduce paid work-related absenteeism and dropout of adolescents from poor households.

Further research is needed to assess whether the above programs are effective at improving education outcomes in Ethiopia, and whether different programs are needed by gender, age, and location.

Funding The research underpinning this article is funded through the Gender and Adolescence: GlobalEvidence (GAGE) research consortium by UK aid.

\section{Declarations}

Conflict of interest On behalf of all authors, the corresponding author states that there is no conflict of interest.

Open Access This article is licensed under a Creative Commons Attribution 4.0 International License, which permits use, sharing, adaptation, distribution and reproduction in any medium or format, as long as you give appropriate credit to the original author(s) and the source, provide a link to the Creative Commons licence, and indicate if changes were made. The images or other third party material in this article are included in the article's Creative Commons licence, unless indicated otherwise in a credit line to the material. If material is not included in the article's Creative Commons licence and your intended use is not permitted by statutory regulation or exceeds the permitted use, you will need to obtain permission directly from the copyright holder. To view a copy of this licence, visit http://creativecommons.org/licen ses/by/4.0/.

\section{References}

Abuya, B., M. Oketch, and P. Musyoka. 2013. Why do pupils dropout when education is 'free'? Explaining school dropout among the urban poor in Nairobi. Compare: A Journal of Comparative and International Education 43 (6): 740-762.

Aghion, P., E. Caroli, and C. Garcia-Penalosa. 1999. Inequality and economic growth: The perspective of the new growth theories. Journal of Economic Literature 37 (4): 1615-1660.

Assaad, R., D. Levison, and N. Zibani. 2007. The Effect of child work on schooling: evidence from Egypt. Working paper No. 2007-04. Minnesota: Minnesota Population Center, University of Minnesota.

Bai, J., and Y. Wang. 2020. Returns to work, child labor and schooling: The income vs. price effects. Journal of Development Economics 145: 102466.

Barro, R. 1997. The Determinants of Economic Growth. Cambridge, MA: MIT Press. 
Basu, K. 1999. Child labor: Cause, consequence, and cure, with remarks on international labor standards. Journal of Economic Literature 37 (3): 1083-1119.

Beegle, K., R. Dehejia, and R. Gatti. 2009. Why should we care about child labor? The education, labor market, and health consequences of child labor. Journal of Human Resources 44 (4): 871-889.

Bergmann, H. 1996. Quality of education and the demand for education: Evidence from developing countries. International Review of Education 42 (6): 581-604.

Boualaphet, K., and H. Goto. 2020. Determinants of school dropout in Lao People's Democratic Republic: A survival analysis. Journal of International Development 32: 961-975.

Cabus, S.J., and K. De Witte. 2015. Does unauthorized school absenteeism accelerates the dropout decision?-Evidence from a Bayesian duration model. Applied Economics Letters 22 (4): 266-271.

Chege, F.N., and D.N. Sifuna. 2006. Girls' and women's education in Kenya: Gender Perspectives and Trends. Paris: UNESCO.

Edmonds, E.V. 2007. Child labor. Handbook of Development Economics 4: 3607-3709.

Evans, D. K., M. Akmal, and P. Jakiela. 2019. Gender Gaps in Education: The Long View. CGD Working Paper No. 523. Washington, DC: Center for Global Development. https://www.cgdev.org/publi cation/gender-gaps-education-long-view

Fergusson, D.M., and L.J. Woodward. 2002. Mental health, educational, and social role outcomes of adolescents with depression. Archives of General Psychiatry 59 (3): 225-231.

Fonagy, P., S. Twemlow, E. Vernberg, F. Sacco, and T. Little. 2005. Creating a peaceful school learning environment: The impact of an antibullying program on educational attainment in elementary schools. Medical Science Monitor: International Medical Journal of Experimental and Clinical Research 11 (7): CR317-CR325.

Getnet, G., and G. Beliyu. 2012. Child labour and child schooling in rural Ethiopia: Nature and trade-off. Education Economics 20 (4): 365-385.

Gibbons, E. D., Huebler, F., \& Loaiza, E. (2005). Child labour, education and the principle of non-discrimination, UNICEF Staff Working Papers, UNICEF, New York.

Glewwe, P., and N. Ilias. 1996. The determinants of school attainment in sub-Saharan Africa: A case study of Ghana. Journal of International Development 8 (3): 395-413.

Goldberg, D., and P. Williams. 1988. A User's Guide to the General Health Questionnaire. Windsor, UK: NFER-Nelson.

Gubbels, J., C.E. van der Put, and M. Assink. 2019. Risk factors for school absenteeism and dropout: A meta-analytic review. Journal of Youth and Adolescence 48 (9): 1637-1667.

Hanushek, E.A. 1979. Conceptual and empirical issues in the estimation of educational production functions. Journal of Human Resources. https://doi.org/10.2307/1455751.

Hicks, J., N. Jones, T. Woldehanna, and S. Baird. 2019. GAGE Ethiopia baseline quantitative research design and sample. Mimeo

Jones, N., Baird, S., Hicks, J., Presler-Marshall, E., Woldehanna, T. and W. Yadete. 2019. Adolescent well-being in Ethiopia: exploring gendered capabilities, contexts and change strategies. A synthesis report on GAGE Ethiopia baseline findings, 2019. London: Gender and Adolescence: Global Evidence.

Kabubo-mariara, J., and D.K. Mwabu. 2007. Determinants of school enrolment and education attainment: Empirical evidence from Kenya. South African Journal of Economics 75 (3): 572-593.

Kearney, C.A. 2008. An interdisciplinary model of school absenteeism in youth to inform professional practice and public policy. Educational Psychology Review 20: 257-282.

Kibriya, S., Z.P. Xu, and Y. Zhang. 2015. The impact of bullying on educational performance in Ghana: A bias-reducing matching approach. Agricultural and Applied Economics Association \& Western Agricultural Economics Association Annual Meeting, July 26-28, 2015 San Francisco, California

King, N., C. Dewey, and D. Borish. 2015. Determinants of primary school non-enrollment and absenteeism: Results from a retrospective, convergent mixed methods, cohort study in rural western Kenya. PLOS ONE 10 (9): e138362.

Lloyd, C.B., and B.S. Mensch. 2008. Marriage and childbirth as factors in dropping out from school: An analysis of DHS data from sub-Saharan Africa. Population Studies 62 (1): 1-13.

Lloyd, M. 2018. Domestic violence and education: examining the impact of domestic violence on young children, children, and young people and the potential role of schools. Frontiers in Psychology 9: 2094.

Macmillan, R., and J. Hagan. 2004. Violence in the transition to adulthood: Adolescent victimization, education, and socioeconomic attainment in later life. Journal of Research on Adolescence 14 (2): $127-158$. 
Makafane, T.D. 2019. The ramifications of bullying in lesotho schools. Journal of Education, Teaching and Social Studies, 1(1).

Marcus, R., J. Rivett, and K. Kruja. 2020. How far do parenting programmes help change norms underpinning violence against adolescents? Evidence from low and middle-income countries. Global Public Health 16 (6): 820-841.

Marcus, R., J. Rivett, and K. Kruja. 2019. What are the impacts of parenting programmes on adolescents? A review of evidence from low and middle-income countries. London: Gender and Adolescence: Global Evidence

McGaha-Garnett, V. 2013. The effects of violence on academic progress and classroom behavior: From a parent's perspective. Ideas and Research You Can Use, VISTAS online, Article 91. Retrived from https://www.counseling.org/docs/defaultsource/vistas/the-effects-of-violence-on-academicprogressand-classroom-behavior.pdf.

Ministry of Education (MoE). 2015. Education Sector Development Programme V (ESDP V) 2015/162019/20. Addis Ababa: Ministry of Education

Ministry of Education (MoE). 2016/17. Education Statistics Annual Abstract, 2009 E.C. (2016/17) Addis Ababa: Ministry of Education

Ministry of Education (MoE). (2020). Education Statistics Annual Abstract September 2019-March 2020, Addis Ababa, Ministry of Education

Ohba, A. 2020. Why do some children still leave primary school early? Comparing reasons in three regions of Kenya. Africa Education Review 17 (2): 33-49.

Okumu, I.M., A. Nakajjo, and D. Isoke. 2008. Socioeconomic determinants of primary school dropout: The logistic model analysis. African Journal of Economic Review 4 (1): 217-241.

Pankhurst, A., T. Woldehanna, M. Araya, Y. Tafere, J. Rossiter, A. Tiumelissan, and K. Birhanu. 2018. Young Lives Ethiopia: Lessons from Longitudinal Research with the Children of the Millennium. Country Report. Oxford: Young Lives.

Pells, K., and Morrow, V. 2017. Children's experiences of violence: evidence from the Young Lives Study in Ethiopia, India, Peru and Vietnam. Background paper. Ending Violence in Childhood Global Report.

Posso, A., and S. Feeny. 2016. Beyond enrolments: The determinants of primary-school attendance in Melanesia. Journal of the Asia Pacific Economy 21 (4): 531-548.

Psaki, S.R., B.S. Mensch, and E. Soler-Hampejsek. 2017. Associations between violence in school and at home and education outcomes in rural Malawi: A longitudinal analysis. Comparative Education Review 61 (2): 354-390.

Putnick, DL., and MH. Bornstein. 2015. "Is child labor a barrier to school enrollment in low- and middleincome countries?"International Journal of Educational Development 41: 112-120.

Ray, R., and G. Lancaster. 2005. The impact of children's work on schooling: Multi-country evidence. International Labour Review 144 (2): 189-210.

Reiss, A., and J. Roth. 1993. Understanding and preventing violence. Washington, DC: National Academy Press.

Rose, P., and S. Al-Samarrai. 2001. Household constraints on schooling by gender: Empirical evidence from Ethiopia. Comparative Education Review 45 (1): 36-63.

Rothon, C., J. Head, C. Clark, E. Klineberg, V. Cattell, and S. Stansfeld. 2009. The impact of psychological distress on the educational achievement of adolescents at the end of compulsory education. Social Psychiatry and Psychiatric Epidemiology 44 (5): 421-427.

Sabates, R., A. Hossain, and K.M. Lewin. 2013. School drop out in Bangladesh: Insights using panel data. International Journal of Educational Development 33 (3): 225-232.

Sabates, R., Westbrook, J., Akyeampong, K., \& Hunt, F. (2010). School dropout: Patterns, causes, changes and policies. Background paper prepared for the EFA Global Monitoring Report 2011. http://unesdoc.unesco.org/images/0019/001907/190771e.pdf

Sahin, S., Z. Arseven, and A. Kiliç. 2016. Causes of student absenteeism and school dropouts. International Journal of Instruction 9 (1): 195-210.

Subrahmanyam, D. 2016. Gender Perspectives on Causes and Effects of School Dropouts from Primary and Secondary Education in Developing Countries-An Overview. Stockholm: Swedish International Development Cooperation Agency

Taniguchi, K. 2015. Determinants of grade repetition in primary school in sub-Saharan Africa: An event history analysis for rural Malawi. International Journal of Educational Development 45: 98-111.

United Nations. 2019. Sustainable Development Goal 4. Retrieved from https://sustainabledevelopment. un.org/sdg4 
Wandera, S.O., K. Clarke, L. Knight, E. Allen, E. Walakira, S. Namy, D. Naker, and K. Devries. 2017. Violence against children perpetrated by peers: A cross-sectional school-based survey in Uganda. Child Abuse and Neglect 68: 65-73.

Wodon, Q., M. Nguyen, and C. Tsimpo. 2016. Child marriage, education, and agency in Uganda. Feminist Economics 22 (1): 54-79.

Woldehanna, T., and A. Hagos. 2015. Economic shocks and children's dropout from primary school: Implications for education policy in Ethiopia. Africa Education Review 12 (1): 28-47.

Wyness, M. 1999. Childhood, agency and education reform. Childhood 6 (3): 353-368.

Ziyn, E. 2012. School-intrinsic impediments in the provision of primary education for nomadic pastoralist afar children in Ethiopia. Mediterranean Center of Social and Educational Research 2 (3): 347-347.

Publisher's Note Springer Nature remains neutral with regard to jurisdictional claims in published maps and institutional affiliations.

\section{Authors and Affiliations}

\section{Tassew Woldehanna ${ }^{1} \cdot K_{\text {Kefyalew Endale }}^{2} \cdot$ Joan Hamory ${ }^{3} \cdot$ Sarah Baird $^{4}$ (D)}

Tassew Woldehanna

tassew.woldehanna@gmail.com

Kefyalew Endale

ekefyalew@gmail.com

Joan Hamory

jhamoryhicks@ou.edu

1 Department of Economics, Addis Ababa University, Addis Ababa, Ethiopia

2 Department of Economics and Institute of Development and Policy Research (IDPR), Addis Ababa University, Addis Ababa, Ethiopia

3 Department of Economics, University of Oklahoma, 308 Cate Center Drive, Cate 1, Norman, OK 73072, USA

4 Department of Global Health, George Washington University, 950 New Hampshire Ave, NW, Washington, DC 20052, USA 